\section{$\angle$ Research Square \\ Preprints are preliminary reports that have not undergone peer review \\ They should not be considered conclusive, used to inform clinical practice, or referenced by the media as validated information.}

\title{
High-coverage Lipidomics Analysis Reveals Biomarkers for Diagnosis of Acute Exacerbation of Chronic Obstructive Pulmonary Disease With Two Traditional Chinese Medicine Syndromes
}

\author{
Xin-guang Liu \\ Henan Univeristy of Chinese Medicine \\ Hai-Long Zhang \\ Henan Univeristy of Chinese Medicine \\ Yi-Mei Si \\ Henan University of Chinese Medicine \\ Yan Du \\ Henan University of Chinese Medicine \\ Jin-Yan Wu \\ Henan Univerisity of Chinese Medicine \\ Jiansheng Li ( li_js8@163.com )
}

Henan University of Chinese Medicine https://orcid.org/0000-0002-6485-2371

\section{Research}

Keywords: Acute exacerbation, Chronic obstructive pulmonary disease, High-coverage lipidomics, Lipid metabolism, Liquid chromatography-quadrupole orbitrap mass spectrometry, TCM syndromes

Posted Date: November 24th, 2021

DOI: https://doi.org/10.21203/rs.3.rs-1057383/v1

License: @ (1) This work is licensed under a Creative Commons Attribution 4.0 International License. Read Full License 


\section{Abstract}

\section{Background}

Traditional Chinese medicine (TCM) is distinguished by syndrome differentiation. Acute exacerbation of chronic obstructive pulmonary disease (AECOPD) is the leading cause of morbidity and mortality in COPD management. Previous studies have proved that AECOPD can be characterized as 2 TCM syndromes, and systematic dialectical treatment showed better curative effect than conventional therapy. However, detecting the progression from the stable stage to acute exacerbation of COPD with different TCM syndromes mainly depends on doctors' judgment of clinical symptoms, and there is no biomarker that can be used for auxiliary clinical diagnosis. This study conducted a high-coverage lipidomics to find biomarker for the early diagnosis of AECOPD with 2 TCM syndromes.

Methods

Serum samples from COPD patients $(n=82)$ and healthy subjects $(n=29)$ were collected and analyzed. Patients with COPD were divided into stable COPD (SCOPD) and AECOPD groups, with the latter comprising TCM syndromes: phlegm-heat congesting lung (PH-CL) and phlegm-damp amassing in the lung (PD-AL). High-coverage lipidomics profiling of 913 lipids belonging to 19 subclasses was carried out by liquid chromatography-quadrupole orbitrap mass spectrometry.

Results

We performed 4 cross-comparisons to characterize metabolic disturbances associated with the progression of stable COPD to AECOPDie, SCOPD vs healthy subjects, AECOPD vs SCOPD, PH-CL-AECOPD vs SCOPD, and PD-AL-AECOPD vs SCOPD. We identified 86 lipids with differential abundance among groups. Lipids that were altered from the stable stage of disease to AECOPD included sphingolipids, ethercontaining glycerophospholipids, phosphatidylglycerols, and glycerol lipids. Three panels of lipid biomarkers specific to AECOPD, two TCM syndromes of AECOPD vs SCOPD yielded areas under the receiver operating characteristic curve of $0.788,0.921$ and 0.920 , respectively, with sensitivity of $77.5 \%, 80.7 \%$ and $91.3 \%$, respectively, and specificity of $75.8 \%, 97.0 \%$ and $87.9 \%$, respectively.

Conclusions

Differences in lipid metabolism may underlie AECOPD and its TCM syndromes, and can serve as biomarkers for early diagnosis.

\section{Introduction}

Chronic obstructive pulmonary disease (COPD) occurs in a minority of smokers and is characterized by intermittent exacerbations and clinical subphenotypes such as emphysema and chronic bronchitis. It is estimated that COPD-related mortality will reach 1 billion by the end of the 21 st century [1,2]. The disease course is mainly divided into stable COPD (SCOPD) and acute exacerbation of COPD (AECOPD). In the former, the symptoms of cough, expectoration, and shortness of breath are stable or mild; in the latter, dyspnea, cough, and expectoration worsen, which is associated with increased morbidity and mortality. Therefore, before or upon acute exacerbation, the clinical management plan must be adjusted to avoid further decline of lung function and death. However, detecting the change from SCOPD to AECOPD depends on doctors' subjective judgment of symptoms as there is no objective basis or biomarker that can be applied to early clinical diagnosis of AECOPD.

Lipid metabolism-including synthesis and oxidation of fatty acids (FAs), lipid esterification, hydrolysis of lipoproteins, synthesis of phosphatidylcholine (PC), and synthesis of prostaglandins and other eicosanoids from arachidonic acid precursors-plays a key role in lung physiology $[3,4]$. An abnormal lipid metabolism phenotype has been linked to COPD. One study showed that COPD was associated with decreases in sphingomyelins (SMs) and ceramides (Cers); meanwhile, plasma Cers was inversely correlated with emphysema and COPD exacerbation was strongly and positively associated with trihexosylceramide level [5]. COPD patients were also found to have increased levels of betaine and choline[2], which play important roles in methyl group metabolism and membrane phospholipid synthesis [6]. FA oxidation-determined by the ratio of carnitine to acylcarnitine-was found to be enhanced in COPD patients; and the ratio of medium- to long-chain carnitines was significantly lower in COPD patients than in healthy subjects [7]. Additionally, smoke exposure was reported to increase FA oxidation by reducing circulating polyunsaturated FAs and enhancing inflammation [8-10]. Elevated plasma levels of FAs are also linked to increased lipid peroxidation $[10,11]$. Thus, lipids are potential biomarkers for the development and progression of COPD.

Traditional Chinese medicine (TCM) is distinguished by syndrome differentiation[12-14]. In TCM, the progression from SCOPD to AECOPD belonging to two dominate causes, phlegm-heat congesting lung (PH-CL) and phlegm-damp amassing in the lung (PD-AL). In other word, 
AECOPD can be divided into 2 TCM syndromes. PH-CL is characterized by cough or intense wheezing; yellow or white sticky phlegm that is difficult to expectorate; fever or thirst and a desire for a cold drink; dry stools; a tongue that is red, with a yellow or greasy coating; and rapid or slippery and rapid pulse. PD-AL is characterized by cough or intense wheezing; shortness of breath; excessive white or foamy phlegm; epigastric fullness; sticky and greasy mouth and poor appetite; white and greasy coating on the tongue; and a slippery or thready and slippery pulse. The 2 TCM syndromes of AECOPD can be distinguished by a standardized method [15] and are treated by different strategies (Qingrehuatan and Zaoshihuatan granules for PH-CL-AECOPD and PH-AL-AECOPD, respectively). In a randomized, double-blind, placebo-controlled trial of 378 patients at 8 centers in China, treatment of the 2 TCM syndromes of AECOPD with the abovementioned herbal medicines achieved a satisfactory clinical effect after 14 days including reductions in COPD assessment, modified British Medical Research Council, and COPD patient-reported outcome scale scores; duration of hospital stay; and number of exacerbations and readmissions [16]. Therefore, it is obvious that different TCM syndromes of AECOPD underlie different pathological processes, thus the biomarkers may be also different in the diagnosis of them. At the same time, realization of dialectical treatment by an early diagnosis of AECOPD with 2 TCM syndromes will be of great help to improve the curative effect of COPD.

In the present study we aimed to identify biomarkers that can be used to detect the progression from SCOPD to AECOPD with two TCM syndromes through a high-coverage lipidomic analysis by ultra-high performance liquid chromatography-quadrupole-orbitrap-mass spectrometry (UHPLC-Q-orbitrap-MS). As a result, this work provides a biomarker panel that can not only detect the exacerbation of COPD, but can also distinguish between AECOPD TCM syndromes, which can improve the personalized management of COPD.

\section{Methods}

\subsection{Chemicals and reagents}

Ammonium acetate, liquid chromatography-mass spectrometry (LC-MS)-grade isopropanol and acetonitrile, and HPLC-grade methanol and methyl tert-butyl ether (MTBE) were purchased from Fisher Scientific (Geel, Belgium). Deionized water was produced with a Milli-Q system (Millipore, Billerica, MA, USA). Lipid standards including PC 15:0-18:1(d7), lyso-PC (LPC) 18:1(d7), phosphatidylethanolamine (PE) 15:0-18:1(d7), lyso-PE (LPE) 18:1(d7), phosphatidylglycerol (PG) 15:0-18:1(d7) (Na salt), phosphatidylinositol (PI) 15:0-18:1(d7) $\left(\mathrm{NH}_{4}\right.$ salt), phosphatidylserine (PS) 15:0-18:1 (d7) (Na salt), triacylglycerol (TG) 15:0-18:1(d7)-15:0, diacylglycerol (DG) 15:0-18:1(d7), cholesterol ester (CE) 18:1(d7), SM 18:1-18:1(d9), Cer C15 (d7), and oleic acid (d9) were purchased from Avanti Polar Lipids (Alabaster, AL, USA).

\subsection{Subjects and study design}

A total of 120 subjects were retrospectively enrolled in this study from August 2018 to January 2020 at The First Affiliated Hospital of Henan University of Chinese Medicine including 29 healthy subjects, 36 patients with SCOPD (Global Initiative for Chronic Obstructive Lung Disease stage $\mathrm{I} / \mathrm{II}$ or $\mathrm{A} / \mathrm{B}$ ), and 55 patients with AECOPD. COPD was diagnosed as described in our previous work [16]. Patients with AECOPD were classified into PH-CL-AECOPD $(n=30)$ and PH-AL-AECOPD $(n=25)$, which were diagnosed as described in our previous work [16] according to the Diagnostic Criteria of TCM Syndromes of Chronic Obstructive Pulmonary Disease (updated in 2011) [17]. Patients with asthma, bronchiectasis, pleural effusion, founder's pneumoconiosis, silicosis, asbestosis, or other diseases that could be confused with COPD were excluded. Thus, the serum samples of 49 patients with AECOPD (PH-CL-AECOPD, n=26; PH-AL-AECOPD, n=23), 33 with SCOPD, and 29 healthy subjects were ultimately used in the lipidomics analysis. Baseline characteristics and clinical parameters of the study population are presented in Tables 1 and 2 .

A fasting blood sample was drawn by venipuncture between $07: 00$ and 09:00 $\mathrm{h}$ and allowed to stand at room temperature for $\geq 60 \mathrm{~min}$ before centrifugation at $3000 \times \mathrm{g}$ for $10 \mathrm{~min}$ at room temperature, and stored at $-80^{\circ} \mathrm{C}$ until use. This study was conducted in accordance with the Declaration of Helsinki and was approved by the ethics committee of The First Affiliated Hospital of Henan University of Chinese Medicine. All participants provided written, informed consent. General information, medical history, smoking history, complications, and the use of medications were recorded. Information on the number of hospitalizations in the past year, pulmonary function in the stable period, serologic indicators at admission, COPD Assessment Test score, and hormone use was also collected. Use of mechanical ventilation, length of hospital stay, routine blood parameters, and other clinical data were recorded at discharge.

\subsection{Sample preparation}

Samples were processed as previously described [18], with minor modifications. Briefly, an equal volume of plasma from each subject was mixed to form a pooled quality control (QC) sample. A 300- $\mu$ volume of cold $\mathrm{MeOH}$ was added to $80 \mu \mathrm{l}$ of QC and test samples, followed by $1 \mathrm{ml}$ of MTBE (containing each deuterated lipid internal standard [IS] at $0.12 \mu \mathrm{g} / \mathrm{ml}$ ). The mixture was vortexed for $10 \mathrm{~s}$ before and after 
adding MTBE. The mixture was then vibrated for $15 \mathrm{~min}$, and $210 \mu \mathrm{l} \mathrm{H}_{2} \mathrm{O}$ was added followed by vortexing for $10 \mathrm{~s}$ to obtain a 2-phase system. After equilibration for $10 \mathrm{~min}$ at $4^{\circ} \mathrm{C}$, the mixture was centrifuged at $13,000 \mathrm{rpm}$ for 10 min at $4^{\circ} \mathrm{C}$. A $400-\mu \mathrm{l}$ volume of supernatant was evaporated to dry in vacuum and stored at $-80^{\circ} \mathrm{C}$ until LC-MS analysis.

\subsection{Lipidomics analysis}

Samples were analyzed using an Ultimate 3000 UHPLC system coupled to a Q-Exactive Orbitrap mass spectrometer (Thermo Fisher Scientific, Bremen, Germany). A reversed-phase ethylene bridged hybrid C8 column (2.1×100 mm, $1.7 \mu \mathrm{m}$; Waters, Milford, MA, USA) was used for chromatographic separation of lipids; the conditions have been previously described [18]. Freeze-dried samples were reconstituted in acetonitrile/isopropanol/ $\mathrm{H}_{2} \mathrm{O}(65: 30: 5, \mathrm{v} / \mathrm{v} / \mathrm{v})$ containing $5 \mathrm{mM}$ ammonium acetate, and $2 \mu \mathrm{l}$ was injected into the LC-MS system. Mass spectrometry data were acquired in both positive and negative ion modes (full scan). The mass spectrometer was operated with a capillary voltage of $3.5 \mathrm{kV}$ in positive mode and $2.5 \mathrm{kV}$ in negative mode. Sheath gas, auxiliary gas, and sweep gas flow rates were set to 50,10 , and 1 arbitrary unit, respectively. The ion transfer tube and vaporizer temperature were set to $325^{\circ} \mathrm{C}$ and $350^{\circ} \mathrm{C}$, respectively. Full-scan MS was conducted at a resolution of $120 \mathrm{~K}$, with automatic gain control target and maximum injection time of $4 \times 10^{5}$ ions and 250 ms, respectively. The scan range was set at a mass-to-charge ratio $(\mathrm{m} / \mathrm{z})$ of $100-1100$. QC samples were regularly inserted into the batch analysis after every 8 real samples.

\subsection{Statistical analysis}

The quantification of 913 target lipids from an in-house accurate mass/ $t_{R}$ library of human serum lipids was performed using Thermo TraceFinder EFS v4.1 software (Thermo Fisher Scientific). The lipids in the library belonged to 19 subclasses of lipid including FA, Cer, hexaglycosylceramide (HexCer), dihexaglycosylceramide (Hex2Cer), SM, LPC, LPC with alkyl substituents (LPC-0), PC, alkyl- and alkenylsubstituted PC (PC-O), PE, LPE, LPE with alkyl substituents (LPE-O), alkyl- and alkenyl-substituted PE (PE-O), PG, PI, PS, DG, TG, and CEs were identified from the QC sample and confirmed by reference standards and/or by MS/MS spectra and $t_{R}$ prediction [18]. The 80\% rule was applied to missing values in each sample group. Each quantified lipid peak area was normalized to both the lipid IS of the corresponding lipid subclass and the QC sample. The resultant normalized peak area of each lipid with relative standard deviation (RSD) $<30 \%$ was used for further data processing.

To evaluate the significance of the abundance of each metabolite, the Shapiro-Wilk parametric hypothesis test was first used to assess the normal distribution of data. Univariate analysis was performed on filtered data in all cross-comparisons with the Mann-Whitney test and Storey $q$ value. The $p$ value across all metabolites within each comparison was adjusted to account for multiple testing with the false discovery rate method, and fold change in all cross-comparisons was also calculated. Projection to latent structures discriminant analysis (PLS-DA) was performed with significant differential metabolites using SIMCA-p software (Umetrics, Umeå, Sweden). Heatmap visualization was carried out using the open access website Morpheus (https://software.broadinstitute.org/morpheus). The threshold for statistical significance was set at $\mathrm{p}<0.05$ and fold change $>1.2$. Logistic regression analysis and receiver operating characteristic (ROC) analysis were applied to the diagnosis of different COPD stages and TCM syndromes. The Student's t test was used to evaluate differences in lipid class/subclass content between groups, and a p value $<0.05$ was considered to be of biological significance.

\section{Results}

\subsection{Baseline characteristics of the study population}

Baseline characteristics and laboratory data of all participants are shown in Tables 1 and 2. COPD patients were older and had a higher proportion of males than healthy subjects, although there were no differences in baseline characteristics between healthy subjects, SCOPD and AECOPD patients ( $p$-value for trend $>0.05$ ). The higher prevalence of COPD in men as compared to women was likely due to the higher proportion of smokers in the former[19]. There were no significant differences in routine clinical indices between different stages of COPD or TCM syndromes of AECOPD. Notably, compared to the SCOPD group, the AECOPD group had more current smokers and higher packyears, though it is not significant ( $p$-value $>0.05)$, indicating that smoking might be related to acute exacerbation of COPD.

\subsection{High-coverage lipidomics analysis by UHPLC-Q-orbitrap-MS}

Lipid coverage and annotation are important considerations in lipidomics analyses because of the high degree of diversity in lipid structures and variability in lipid levels. In this work, we achieved a high coverage of lipidome by combining manual identification using MS/MS spectra and validation based on predicted $t_{R}$. The protocol is outlined in Figure 1 using DG as an example. In step 1 , a library of precursor ions of all theoretical existing lipids was constructed and extracted from the MS1 spectrum of mixed human serum. For

Page $4 / 25$ 
example, DGs are composed of glycerol and 2 FA chains and were identified by the number of carbons and number of double bonds in the 2 acyl chains without considering the position of the substituted FA and unsaturated bond. In mammals, the number of carbons in a single lipid acyl chain varies from 10 to 26 , and the number of acyl chain double bonds ranges from 0 to 6 . Based on this rule, we inferred the precursor ion information of all theoretically existing DGs and extracted these from the MS1 spectrum of mixed serum to obtain preliminary data on DGs. In step 2, the lipids identified in step 1 were confirmed based on MS/MS spectra, and only lipids showing fragments of the polar fraction (if they existed) and characteristic fragments of FA were retained. In conventional automatic MS/MS matching with the database, characteristic fragments may have a very weak signal, leading to false identification. We therefore optimized the MS parameters and manually performed MS/MS spectrum matching. For each DG, $[\mathrm{M}+\mathrm{H}-\mathrm{FA}-1]^{+}$and $[\mathrm{M}+\mathrm{H}-\mathrm{FA}-2]^{+}$were the characteristic fragments; those used for other lipids are shown in Supplementary Table 1. A structure vs $t_{R}$ relationship can be constructed within a specific class/subclass of lipids based on the observation that the $t_{R}$ of lipids with the same number of double bonds increases linearly with increasing acyl chain carbon number, and the $t_{R}$ of lipids with the same carbon number decreases linearly with increasing acyl chain double bond number. Thus, in step 3 we performed these 2 linear validations on the lipids identified based on the MS/MS spectra, and compared the experimentally derived $t_{R}$ of lipids with the value predicted by the obtained linear equation. A good overall linear performance $\left(\mathrm{R}^{2}=0.9952\right.$ [0.9659-1]) was observed for all lipid subclasses; an experimental $t_{R}$ with an error within 0.5 min was obtained for 875 out of 913 tested lipids. The average and median prediction errors of the tested lipids were 8.3 and $3.6 \mathrm{~s}$, respectively, confirming the results of our lipid identification based on the chromatographic $t_{R}$. Ultimately, 913 lipids were identified in the mixed human serum based on this protocol that belonged to 19 lipid subclasses including FAs, Cers, HexCers, Hex2Cers, SMs, LPCs, LPC-Os, PCs, PC-Os, LPEs, LPE-Os, PEs, PE-Os, PGs, PIs, PSs, DGs, TGs, and CEs, the ID, $m / z, t_{R}$ and fragments of all identified lipids were shown in Supplementary Table 1 and Figure 1D.

\subsection{Detection of lipids by nontargeted lipidomics profiling}

The same lipidomics approach was used to identify candidate serum lipid biomarkers in patients with COPD of different stages and TCM syndromes. Serum lipid extracts of all participants were randomly analyzed by UHPLC-Q-orbitrap MS with full scan acquisition in both positive and negative ion modes; representative chromatograms of different groups of samples are shown in Figures S1 and S2, respectively. Extracted ion chromatograms were obtained for the lipids from the in-house lipid library. Because only the MS1 precursor ion was used to quantify the lipids, many lipid isomers (differing only in their MS/MS spectra) with similar $t_{R}$ could not be separated well; these lipids were therefore combined into a single lipid group with same $t_{R}$ and $\mathrm{m} / \mathrm{z}$. Thus, 499 lipids or lipid groups were included in the library for peak extraction. After peak integration, 402 lipids were quantified in $80 \%$ of serum samples (signal/noise $>10$ ). After IS and QC normalization, 262 lipids with RSD $<30 \%$ were selected for subsequent statistical analyses.

\subsection{Differential expression of lipid class/subclass between COPD patients and healthy subjects}

To investigate changes in the lipid pool, the total content of each lipid class/subclass was determined for each sample; for each lipid, this was calculated as its peak area divided by that of the IS of the same subclass $\left(C_{\text {perlS }}\right)$ (Figure 2$)$. As the ISs for each subclass had the same concentration, the relative contents of different lipid classes/subclasses were comparable. The percentage of each subclass in total lipids was recorded as $C \%$ (Figure 3 ). Compared to healthy subjects, the $C_{\text {perls }}$ of total lipids was decreased in patients with SCOPD, and effect that was enhanced in both AECOPD TCM syndromes (Figure 2A) meanwhile, the decrease in total lipid was not statistically significant. The difference in total lipids between SCOPD and controls was mainly due to the differential abundance of TGs, as these accounted for the largest proportion of identified species (318 out of 913 ) and had the highest total content. $C_{\text {perls }}$ of most lipid subclasses was lower in SCOPD patients than in healthy subjects although the difference was only significant for CEs (Figure 2B); meanwhile, the $C \%$ of SMs and PC-Os was significantly increased (Figure 3).

The differences in the abundance of lipid classes were greater between AECOPD and SCOPD groups, and the 2 TCM syndromes of AECOPD also showed significant differences. Serum sphingolipids (including Cers and SMs) showed a lower $C_{\text {perls }}$ but a higher $C \%$ in AECOPD as compared to SCOPD patients. PH-CL-AECOPD showed increased $C \%$ and $C_{\text {perls }}$ of SMs and decreased $C_{\text {perls }}$ and $C \%$ of Cers. PH-AL-AECOPD also showed increased $C \%$ and $C_{\text {perls }}$ of SMs, but $C_{\text {perls }}$ of Cers was decreased whereas $C \%$ of Cers was increased. Sphingolipids showing differential abundance included [SM d18:1_18:2 \& SM d18:2_18:1] and [SM d17:1_24:1 \& SM d18:1_23:1 \& SM d18:2_23:0], etc. $C_{\text {perIS }}$ and $C \%$ of PGs were reduced in PH-AL-AECOPD patients. Ether-containing glycerophospholipids (PE-Os and PC-Os) were decreased (both $C_{\text {perlS }}$ and $C \%$ ) in PH-CL-AECOPD. Differential ether-containing glycerophospholipids included PC-0 16:0e_20:3, PC-0 16:1_16:0p, PE-0 18:2p_22:6, PC-0 16:0_16:0p, PE-0 16:0p_22:5-1, PE-0 16:0p_22:4, and PC-0 16:0p_18:2. Additionally, compared to the stable stage, both $C_{\text {perls }}$ and $C \%$ of serum glycerol lipids-especially TGs-were decreased in AECOPD patients of both TCM syndromes; however, due to the large variation within groups, changes in TG content were not significant (Figures 2 and 3 ).

Page 5/25 


\subsection{Cross-comparisons of patients with COPD of different stage and TCM syndromes}

We compared the SCOPD patients to healthy subjects and identified 86 lipids that were significantly altered $(p<0.05$, fold change $>1.2)[20]$. We used the PLS-DA model to characterize metabolic disturbances. Ions with variable importance in projection (VIP) values $>1.0$ were considered candidate differential metabolites [20]. There were 32 lipids that were differentially expressed between the 2 groups (Table S2). The 3-dimensional (3D) scatterplots showed obvious differences between SCOPD patients and controls (Figure 4A), with a cumulative R2Y of 0.635 and Q2 of 0.507 . Additionally, 107 lipids were significantly altered and 48 were identified as differential lipids between the SCOPD and AECOPD groups (Table S3). This was confirmed by the 3D scatterplot (Figure 4B) with a cumulative of R2Y 0.579 and Q2 of 0.512 .

We examined the lipidomic profiles of PH-CL-AECOPD and PH-AL-AECOPD patients and found that 147 and 131 lipids, respectively, were significantly altered compared to the SCOPD group, of which 50 and 43, respectively, were identified as differential lipids (Tables S4 and S5). The differences between AECOPD and SCOPD were apparent in the PLS-DA 3D scatterplot (Figure 4C, D), with a cumulative R2Y of 0.598 and Q2 of 0.506 for PH-CL-AECOPD vs SCOPD and cumulative R2Y of 0.612 and Q2 of 0.495 for PH-AL-AECOPD vs SCOPD. The PLS-DA 3D scatterplot is shown in Figure 4A-D. Through cross-comparisons between patients with COPD of different stages and TCM syndromes and healthy subjects, we identified 118 differential lipids; the Venn diagram and heatmap of average normalized quantities of the differential lipids are shown in Figures $4 \mathrm{E}$ and 5. Cluster analysis showed that there were significant differences in the levels of lipid biomarkers between COPD patients and healthy subjects and between SCOPD and AECOPD patients. The Venn diagram revealed some lipid markers common to TCM syndromes of AECOPD and to AECOPD and SCOPD, but there were more markers that differed among these groups that could potentially be used for differential diagnosis.

\subsection{Differential diagnosis based on metabolic biomarkers}

Accurate diagnosis of COPD stage is critical for deciding the appropriate therapeutic strategy for patients; the correct identification of TCM syndromes of AECOPD is also important for personalized COPD treatment. For differential diagnosis of COPD using lipidomics-based biomarkers, we used the criteria of VIP $>1.2$, adjusted $p$ value $<0.05$, and fold change $>1.2$. In our lipidomics analysis, there were 15 lipid biomarkers that could distinguish between SCOPD and controls as well as 21 for AECOPD vs SCOPD, 21 for PH-CL-AECOPD vs SCOPD, and 20 for PH-AL-AECOPD vs SCOPD (Table 3).

In the ROC analysis based on logistic regression of 4 biomarker panels, the area under the ROC curve (AUC), sensitivity, and specificity were $0.917,93.9 \%$, and $75.9 \%$, respectively, for SCOPD vs health subjects; $0.788,77.5 \%$, and $75.8 \%$, respectively, for AECOPD vs SCOPD; 0.921 , $80.7 \%$, and $97.0 \%$, respectively, for PH-CL-AECOPD vs SCOPD; and $0.920,91.3 \%$, and $87.9 \%$, respectively, for PH-AL-AECOPD vs SCOPD (Figure 6A). Based on the highest prediction sensitivity and specificity values from the ROC analysis, the optimal cutoff values were 0.422 for distinguishing SCOPD from healthy subjects, 0.591 for AECOPD vs SCOPD, 0.388 for AECOPD PH-CL-AECOPD vs SCOPD, and AECOPD 0.715 for PH-AL-AECOPD vs SCOPD (Figure 6B). Notably, the sensitivity and specificity values for diagnosing PH-CL-AECOPD or PH-ALAECOPD from SCOPD were much higher than the values for diagnosing AECOPD (2 TCM syndromes combined) from SCOPD.

\section{Discussion}

Dialectical treatment is the core of TCM theory, but in the past, the discrimination of TCM syndrome still lacking scientific clinical indicators, which mainly depended on the subjective judgment of doctors. Therefore, the requirements for doctors' ability in TCM clinic are extremely high. Because TCM syndrome is difficult to be simulated on animal models, the analysis of clinical samples has become an important means to analyze the scientific basis for TCM syndrome differentiation. In this study we carried out a comprehensive lipidomic analysis of COPD patients at stable and acute exacerbation stages, with the latter classified into 2 TCM syndromes (Figure 7). The lipidomics profiling revealed significant differences between COPD patients and healthy subjects and across different COPD stages and TCM syndromes. The 118 significantly altered lipids in the serum samples suggested that COPD involves a universal disturbance in lipid metabolism. Interestingly, combinations of lipid biomarkers showed better predictive value for distinguishing PH-CL-AECOPD or PH-ALAECOPD from SCOPD than for distinguishing AECOPD (the 2 TCM syndromes combined) from SCOPD. These results suggest that the proposed TCM syndromes of AECOPD have distinct lipid metabolism phenotypes that may be overlooked when patients are treated patients without differentiating between TCM syndromes. Moreover, differences in lipid metabolism may reflect distinct pathologic characteristics of TCM syndromes in AECOPD, that require specific treatment approaches.

Most of the observed differences in lipid metabolism between SCOPD patients and healthy subjects were not statistically significant. An exception was the decrease in CEs in the former group, although it is unclear whether this was an actual phenomenon because few CEs with high signal intensity were detected by MS. The more significant differences were between AECOPD and SCOPD, and sphingolipid metabolism was found as one important altered pathway. Sphingolipids are primarily found in cell membranes but also in biofluids such 
as plasma and serum and are involved in diverse biologic processes including cell death, proliferation, differentiation, autophagy, senescence, migration, and efferocytosis [21]. Sphingolipid metabolism was shown to be dysregulated by smoking and COPD[22-24]. In the present study, the $C \%$ of sphingolipids was increased in COPD, especially in PH-AL-AECOPD; this is consistent with the findings that smokers [22] and COPD patients [23] had increased Cer levels in the lung and that sphingolipids in the sputum were elevated in COPD [24]. The excessive Cers enhanced pulmonary vascular cell apoptosis [25] and decreased clearance of apoptotic cells by alveolar macrophages [26], which exacerbated lung injury. However, the $C_{\text {perls }}$ of sphingolipids was decreased in AECOPD, likely because in the stable stage of disease, sphingolipid synthesis was enhanced due to lung injury but in the acute aggravation stage, aggravation of the damage resulted in low lung mass and metabolic deficiency, which decreased sphingolipid levels. It was reported that a lower forced expiratory volume in COPD was associated with lower plasma SMs [5,27]. Cers may be generated from SMs by activated plasma sphingomyelinases [28] and mediate outside-in signaling [29], and/or be further metabolized to sphingosine by plasma ceramidases. To the extent that serum levels reflect cellular metabolism, the decrease in both SMs and Cers suggests that low SM levels are not caused by inhibition of SM synthase (which would result in Cer accumulation), but are due to decreased availability of precursor Cers. Under these conditions, SM supplementation may enhance Cers production and catabolism. This may explain the role of sphingolipid metabolism in the specific pathologic TCM syndromes of AECOPD, as C\% of Cers was significantly higher in PH-AL-AECOPD than in PH-CL-AECOPD. Thus, PH-AL-AECOPD may be distinguished by enhanced pulmonary vascular cell apoptosis, although this requires validation in additional studies.

PGs were also decreased in AECOPD, especially in PH-AL-AECOPD. PGs function as a pulmonary surfactant-which is important for gas exchange and optimal respiratory function-and participate in the organization of the surfactant complex, immunomodulation, and host defense; it was reported that in COPD, surface lipid levels were decreased by $60 \%$ and PG levels were significantly reduced in the bronchoalveolar lavage fluid [30]. The decreased PG levels in AECOPD patients in our study-which was observed only in PH-AL-AECOPDmay be due to airway damage caused by surfactant insufficiency. Thus, the decreases in sphingolipids and PGs suggest more serious lung damage in PH-AL-AECOPD than in PH-CL-AECOPD.

AECOPD patients (especially those with $\mathrm{PH}-\mathrm{CL}$ ) showed a decrease in ether-containing glycerophospholipids, which are important plasma membrane components with multiple functions [31,32]. Plasmalogen content may be reduced by peroxisomal dysfunction, oxidative stress, or phospholipase (especially phospholipase A2) activation [33]. Oxidative stress is enhanced in the execution of COPD, leading to further lung inflammation and dysfunction. PH-CL-AECOPD is known to be associated with increased oxidative stress and inflammation: white blood cell count, neutrophil-to-lymphocyte ratio, platelet count [34-36], and serum levels of inflammatory cytokines including interleukin (IL)-8, interferon (IFN)- $\gamma$, and tumor necrosis factor (TNF)-a [37] were reported to be higher as compared to PH-AL-AECOPD. This was supported by our patients' baseline characteristics (Table 2) and clinical data of PH-CL-AECOPD (Table 1). In TCM, PH-CL-AECOPD is characterized by fever, yellow or white sticky phlegm, red tongue, and a yellow or greasy coating on the tongue; these are symptoms of a bacterial or viral infection, which is linked to increased oxidative stress and inflammation. Meanwhile, serum lymphocyte level was found to be lower in PH-CL-AECOPD than in PH-AL-AECOPD [38], suggesting that the former is more susceptible to infection. Taken together, the evidence to date indicates that an enhanced inflammatory response is a pathologic feature of PH-CL-AECOPD.

Serum glycerolipids were decreased in AECOPD of both TCM syndromes. The large variation among AECOPD patients may have been due to the small sample size and differences in blood lipid levels in patients with comorbidities. The observed decrease in TGs in COPD patients was consistent with previous reports [39,40], including a cross-sectional study in a high-risk population of 350,000 adults [41].

We selected several lipid panels to distinguish different stages of COPD and 2 different TCM syndromes of AECOPD. In clinical practice, lipid biomarkers can be used to detect the progression of SCOPD to AECOPD. At present, AECOPD is mainly diagnosed based on obvious clinical indicators such as increased dyspnea, sputum purulence and volume, and coughing or wheezing, and there are no objective and quantifiable indices that are available. The detection of lipid biomarkers specific to AECOPD can help clinicians identify cases that require timely intervention and possible adjustment of the treatment strategy. Lipid biomarkers can also be useful for differentiating between pathologic TCM syndromes of AECOPD that differ in terms of metabolic profile, which can affect clinical outcome. Notably, lipid biomarkers had higher sensitivity and specificity for distinguishing PH-CL-AECOPD or PH-AL-AECOPD from SCOPD than for distinguishing AECOPD (the 2 TCM syndromes combined) from SCOPD. By accurately diagnosing different TCM syndromes of AECOPD, a more personalized and effective management approach can be implemented that can lead to improved clinical outcomes. In our experience, Qingrehuatan and Zaoshihuatan granules have been used to treat patients with PH-CL-AECOPD and PH-AL-AECOPD, respectively, with satisfactory therapeutic effects [16].

\section{Conclusions}


We performed a high-coverage lipidomics analysis of COPD patients to identify changes in lipid profiles in the progression of SCOPD to AECOPD as well as differences in lipid metabolism between AECOPD characterized by distinct TCM syndromes. PH-CL-AECOPD is characterized as lower level of PC-Os and PE-Os, which indicating increased inflammation and oxidative stress. PH-AL-AECOPD is characterized as lower level of PGs and higher level of Cers, which indicating increased Pulmonary surfactant damage and cell apoptosis. Our results provide insight into the pathogenesis of AECOPD and can facilitate screening for COPD patients at risk for disease exacerbation who may require alternative treatments to avoid severe lung dysfunction.

\section{Abbreviations}

3D, 3-dimensional; AECOPD, acute exacerbation of chronic obstructive pulmonary disease; AUC, area under the receiver operating characteristic curve; CE, cholesterol ester; Cer, ceramide; COPD, chronic obstructive pulmonary disease; DG, diacylglycerol; FA, fatty acid; Hex2Cer, dihexaglycosylceramide; HexCer, hexaglycosylceramide; IS, internal standard; LC-MS, liquid chromatography-mass spectrometry; LPC, lyso-phosphatidylcholine; LPC-O, lyso-phosphatidylcholine with alkyl substituents; LPE, lyso-phosphatidylethanolamine; LPE-O, lysophosphatidylethanolamine with alkyl substituents; MS/MS, tandem mass spectrometry; MTBE, methyl tert-butyl ether; PC, phosphatidylcholine; PC-O, alkyl- and alkenyl-substituted phosphatidylcholine; PE, phosphatidylethanolamine; PE-O, alkyl- and alkenylsubstituted phosphatidylethanolamine; PG, phosphatidylglycerol; PI, phosphatidylinositol; PLS-DA, projection to latent structures discriminant analysis; PS, phosphatidylserine; QC, quality control; ROC, receiver operating characteristic; RSD, relative standard deviation; SCOPD, stable chronic obstructive pulmonary disease; SM, sphingomyelin; TCM, traditional Chinese medicine; TG, triacylglycerol; tR, retention time; UHPLC-Q-orbitrap-MS, ultra-high performance liquid chromatography-quadrupole-orbitrap-mass spectrometry; VIP, variable importance in projection.

\section{Declarations}

\section{Ethics approval and consent to participate}

This study was conducted in accordance with the Declaration of Helsinki and was approved by the ethics committee of The First Affiliated Hospital of Henan University of Chinese Medicine. All participants provided written, informed consent.

\section{Consent for publication}

All the authors listed have approved the manuscript and have declared that no competing interest exists.

\section{Author contribution}

X. G. Liu and H. L. Zhang contributed equally

X. G. Liu: Data acquisition; Data analysis; Writing and revising the work

H. L. Zhang: Data acquisition; Data verification; Revising the work

Y. M. Si: Data collection

Y. Du: Data acquisition

J. Y. Wu: Data acquisition

J. S. Li: Interpretation of data for the work; Data verification and Drafting; Conception and design of the work.

\section{Funding}

This work was supported by National Natural Science Foundation of China (No. 81830116, 81973781 and 81603556), and China Postdoctoral Science Foundation (No. 2019M662501), Key R \& D and Promotion Projects in Henan Province (No. 202102310170).

\section{Availability of data and material}

The data used to support the findings of this study are given in the main text and supplementary materials.

\section{Competing interests}


The authors have declared that no competing interest exists.

\section{Acknowledgement}

Not applicable.

\section{References}

1. N Mohammadtursun, Li, Q, Abuduwaki, M, et al. Loki zupa alleviates inflammatory and fibrotic responses in cigarette smoke induced rat model of chronic obstructive pulmonary disease. Chin Med 2020; 15): 92.

2. DJ Adamko, Nair, P, Mayers, I, et al. Metabolomic profiling of asthma and chronic obstructive pulmonary disease: A pilot study differentiating diseases. J Allergy Clin Immunol 2015; 3(136): 571-580 e573.

3. F Yan, Wen, Z, Wang, R, et al. Identification of the lipid biomarkers from plasma in idiopathic pulmonary fibrosis by Lipidomics. BMC Pulm Med 2017; 1(17): 174.

4. M Merino Salvador, Gómez de Cedrón, M, Moreno Rubio, J, et al. Lipid metabolism and lung cancer. Crit Rev Oncol Hematol 2017; (112): 31-40.

5. RP Bowler, Jacobson, S, Cruickshank, C, et al. Plasma sphingolipids associated with chronic obstructive pulmonary disease phenotypes. Am J Respir Crit Care Med 2015; 3(191): 275-284.

6. M Lever \& Slow, S. The clinical significance of betaine, an osmolyte with a key role in methyl group metabolism. Clin Biochem 2010; 9(43): 732-744.

7. S Naz, Kolmert, J, Yang, M, et al. Metabolomics analysis identifies sex-associated metabotypes of oxidative stress and the autotaxin-lysoPA axis in COPD. Eur Respir J 2017; 6(49):

8. S Carraro, Bozzetto, S, Giordano, G, et al. Wheezing preschool children with early-onset asthma reveal a specific metabolomic profile. Pediatr Allergy Immunol 2018; 4(29): 375-382.

9. BK Puri, Treasaden, IH, Cocchi, M, et al. A comparison of oxidative stress in smokers and non-smokers: an in vivo human quantitative study of n-3 lipid peroxidation. BMC psychiatry 2008; Suppl 1(8 Suppl 1): S4.

10. D Baldassarre, Amato, M, Frigerio, B, et al. Impact of cigarette smoking on the plasma fatty acid profile and their interaction in determining the burden of subclinical atherosclerosis. Nutrafoods 2014; 4(13): 159-167.

11. MM Adeva-Andany, Carneiro-Freire, N, Seco-Filgueira, M, Fernández-Fernández, C \& Mouriño-Bayolo, D. Mitochondrial $\beta$-oxidation of saturated fatty acids in humans. Mitochondrion 2019; 46): 73-90.

12. J Wen, Ma, X, Niu, M, et al. Metabolomics coupled with integrated approaches reveal the therapeutic effects of higenamine combined with [6]-gingerol on doxorubicin-induced chronic heart failure in rats. Chin Med 2020; 1(15): 120.

13. E Yan, Song, J, Liu, C \& Hong, W. A research on syndrome element differentiation based on phenomenology and mathematical method. Chin Med 2017; 12): 19.

14. S Ren, Meng, F, Liu, Y, et al. Effects of external application of compound Qingbi granules on acute gouty arthritis with dampnessheat syndrome: a randomized controlled trial. Chin Med 2020; 1(15): 117.

15. IMBoCSoCMPDBoCSoC Medicine. Diagnostic criteria of TCM syndromes of chronic obstructive pulmonary disease (update 2011). J. Trad. Chin. Med. 2012; 2(53): 177-178.

16. J Li, Zhang, H, Ruan, H, et al. Effects of Chinese Herbal Medicine on Acute Exacerbations of COPD: A Randomized, PlaceboControlled Study. Int J Chron Obstruct Pulmon Dis 2020; 15): 2901-2912.

17. IMBoCSOCMPDBoCSoC Medicine. Diagnostic criteria of TCM syndromes of chronic obstructive pulmonary disease (update 2011). J. Trad. Chin. Med. 2012; 2(53): 80-84. 
18. Q Xuan, Hu, C, Yu, D, et al. Development of a High Coverage Pseudotargeted Lipidomics Method Based on Ultra-High Performance Liquid Chromatography-Mass Spectrometry. Anal Chem 2018; 12(90): 7608-7616.

19. H Xu, Ling, M, Xue, J, et al. Exosomal microRNA-21 derived from bronchial epithelial cells is involved in aberrant epitheliumfibroblast cross-talk in COPD induced by cigarette smoking. Theranostics 2018; 19(8): 5419-5433.

20. Y Fan, Li, Y, Chen, Y, et al. Comprehensive Metabolomic Characterization of Coronary Artery Diseases. J Am Coll Cardiol 2016; 12(68): 1281-1293.

21. YA Hannun \& Obeid, LM. Principles of bioactive lipid signalling: lessons from sphingolipids. Nat Rev Mol Cell Bio/2008; 2(9): 139150.

22. T Zhang, Yan, T, Du, J, Wang, S \& Yang, H. Apigenin attenuates heart injury in lipopolysaccharide-induced endotoxemic model by suppressing sphingosine kinase 1/sphingosine 1-phosphate signaling pathway. Chem Biol Interact 2015; (233): 46-55.

23. MC Scarpa, Baraldo, S, Marian, E, et al. Ceramide expression and cell homeostasis in chronic obstructive pulmonary disease. Respiration 2013; 4(85): 342-349.

24. ED Telenga, Hoffmann, RF, Ruben, tK, et al. Untargeted lipidomic analysis in chronic obstructive pulmonary disease. Uncovering sphingolipids. Am J Respir Crit Care Med 2014; 2(190): 155-164.

25. DN Petrusca, Van Demark, M, Gu, Y, et al. Smoking exposure induces human lung endothelial cell adaptation to apoptotic stress. Am J Respir Cell Mol Biol 2014; 3(50): 513-525.

26. DN Petrusca, Gu, Y, Adamowicz, JJ, et al. Sphingolipid-mediated inhibition of apoptotic cell clearance by alveolar macrophages. J Biol Chem 2010; 51(285): 40322-40332.

27. FS Ahmed, Jiang, XC, Schwartz, JE, et al. Plasma sphingomyelin and longitudinal change in percent emphysema on CT. The MESA lung study. Biomarkers 2014; 3(19): 207-213.

28. M Levy, Khan, E, Careaga, M \& Goldkorn, T. Neutral sphingomyelinase 2 is activated by cigarette smoke to augment ceramideinduced apoptosis in lung cell death. Am J Physiol Lung Cell Mol Physiol 2009; 1(297): L125-133.

29. TR Medler, Petrusca, DN, Lee, PJ, et al. Apoptotic sphingolipid signaling by ceramides in lung endothelial cells. Am J Respir Cell Mol Biol 2008; 6(38): 639-646.

30. CW Agudelo, Kumley, BK, Area-Gomez, E, et al. Decreased surfactant lipids correlate with lung function in chronic obstructive pulmonary disease (COPD). PLoS One 2020; 2(15): e0228279.

31. AA Farooqui \& Horrocks, LA. Plasmalogens: workhorse lipids of membranes in normal and injured neurons and glia. Neuroscientist 2001; 3(7): 232-245.

32. B Engelmann. Plasmalogens: targets for oxidants and major lipophilic antioxidants. Biochem Soc Trans 2004; Pt 1(32): 147-150.

33. C Stegemann, Pechlaner, R, Willeit, P, et al. Lipidomics profiling and risk of cardiovascular disease in the prospective populationbased Bruneck study. Circulation 2014; 18(129): 1821-1831.

34. CK Jla, Ying, LZ \& Dong, LX. Relationship between TCM Syndrome patterns and physicochemical parameters of chronic obstructive pulmoary disease: A report of 500 cases. Journal of Ghuangzhou University of Traditional Chinese Medicine 2002; 2(19): 101104.

35. LP Shan. Study of Correlation of Acute Exacerbation of Chronic Obstructive Pulmonary Disease Syndrome Differentiation and Inflammatory Factors. Liaoning Journal of Traditional Chinese Medicine 2018; 8(45): 1676-1678.

36. ZJ Biao, Lei, P, Yan, ZW, et al. Study on correlativity between TCM syndrome differentiation-typing and laboratory indexes of chronic obstructive pulmonary disease. Shangxi J oF TCM 2020; 4(36): 53-55.

37. ZS Han, Gang, DZ \& Hua, ZS. Study on Inflammatory Factors in Patient with Syndrome of Phlegm-heat Obstructing Lung at AECOPD. Journal of Herbei TCM Pharmcology 2016; 2(31): 7-8,16.

Page $10 / 25$ 
38. K Jia. Guangzhou University of Chinese Medicine (2018).

39. W Ruan, Yan, C, Zhu, H, et al. Downregulated level of insulin in COPD patients during AE; role beyond glucose control? Int J Chron Obstruct Pulmon Dis 2019; 14): 1559-1566.

40. $\quad C L i, Y a n, L \&$ Song, J. Plasma level of chemerin in COPD patients and the relationship between chemerin and lipid metabolism. Zhong Nan Da Xue Xue Bao Yi Xue Ban 2016; 7(41): 676-683.

41. H Rayyan Assi, Ziv, A \& Dankner, R. The metabolic syndrome and its components are differentially associated with chronic diseases in a high-risk population of 350000 adults: A cross-sectional study. Diabetes Metab Res Rev 2019; 4(35): e3121.

\section{Tables}

Table 1. Baseline characteristics of the study population

\begin{tabular}{llllll} 
& $\begin{array}{l}\text { Healthy subjects } \\
(\mathrm{n}=29)\end{array}$ & $\begin{array}{l}\text { SCOPD } \\
(\mathrm{n}=33)\end{array}$ & $\begin{array}{l}\text { PH-CL-AECOPD } \\
(\mathrm{n}=23)\end{array}$ & $\begin{array}{l}\text { PH-AL-AECOPD } \\
(\mathrm{n}=26)\end{array}$ & $\begin{array}{l}\text { P value for } \\
\text { trend }\end{array}$ \\
\hline Age, years & $62(40-79)$ & $65(40-79)$ & $64(56-78)$ & $67.5(51-78)$ & 0.179 \\
\hline Sex, \% men & $17(58.62 \%)$ & $27(81.81 \%)$ & $17(73.91 \%)$ & $20(76.92 \%)$ & 0.16 \\
\hline Body mass index & $\begin{array}{l}23.88(19.88- \\
27.09)\end{array}$ & $\begin{array}{l}24.34(20.32- \\
35.92)\end{array}$ & $\begin{array}{l}22.99(17.10- \\
34.29)\end{array}$ & $\begin{array}{l}23.05(15.42- \\
28.93)\end{array}$ & 0.551 \\
\hline $\begin{array}{l}\text { Course of COPD, } \\
\text { months }\end{array}$ & 0 & $48(1-240)$ & $82(1-480)$ & $91(6-264)$ & -
\end{tabular}

AECOPD, acute exacerbation of chronic obstructive pulmonary disease; COPD, chronic obstructive pulmonary disease; $\mathrm{PH}-\mathrm{CL}$, phlegmheat congesting lung; PH-AL, phlegm-damp amassing in the lung; SCOPD, stable chronic obstructive pulmonary disease;

Table 2. Clinical parameters of chronic obstructive pulmonary disease patients

\begin{tabular}{|c|c|c|c|c|c|}
\hline & $\begin{array}{r}\text { SCOPD } \\
(n=33)\end{array}$ & $\begin{array}{l}\text { AECOPD } \\
(n=49)\end{array}$ & $\begin{array}{l}\text { PH-CL-AECOPD } \\
(\mathrm{n}=23)\end{array}$ & $\begin{array}{l}\text { PH-AL-AECOPD } \\
(\mathrm{n}=26)\end{array}$ & $P$ value \\
\hline Current smoker, $\%$ & $3(10 \%)$ & $10(20.4 \%)$ & $3(15 \%)$ & $7(26.92 \%)$ & 0.974 \\
\hline Pack-years & $20(0-1600)$ & $800(0-3200)$ & $460(0-3200)$ & $381(0-1800)$ & 0.859 \\
\hline \multicolumn{6}{|l|}{ GOLD classification } \\
\hline I & $3(9.1 \%)$ & NA & NA & NA & - \\
\hline II & $11(33.33 \%)$ & NA & NA & NA & - \\
\hline III & $7(21.21 \%)$ & NA & NA & NA & - \\
\hline IV & $0(0 \%)$ & NA & NA & NA & - \\
\hline Coronary heart disease & $2(6.06 \%)$ & $8(16.32 \%)$ & $4(17.39 \%)$ & $4(12.12 \%)$ & 0.325 \\
\hline Diabetes & $2(6.06 \%)$ & $6(12.24 \%)$ & $3(13.04 \%)$ & $3(9.09 \%)$ & 0.497 \\
\hline Hypertension & $6(18.18)$ & $6(12.24 \%)$ & $4(17.39 \%)$ & $2(6.06 \%)$ & 0.149 \\
\hline Number of aggravations in the past year & $1(0-3)$ & $1(0-5)$ & $1(0-4)$ & $1(0-5)$ & - \\
\hline White blood cell $\left(\times 10^{9} / \mathrm{I}\right)$ & $6.69 \pm 2.01$ & $6.84 \pm 2.19$ & $7.11 \pm 2.45$ & $6.60 \pm 1.85$ & 0.672 \\
\hline Neutrophil/lymphocyte (\%) & $61.72 \pm 7.74$ & $67.71 \pm 11.78$ & $67.18 \pm 12.65$ & $68.17 \pm 10.67$ & 0.049 \\
\hline Hemoglobin $(\mathrm{g} / \mathrm{l})$ & $148.1 \pm 12.26$ & $143.71 \pm 15.89$ & $142.30 \pm 17.09$ & $144.96 \pm 14.31$ & 0.359 \\
\hline Platelet $\left(\times 10^{9} / \mathrm{I}\right)$ & $197.45 \pm 50.14$ & $201.32 \pm 66.01$ & $210.72 \pm 70.98$ & $193 \pm 58.65$ & 0.574 \\
\hline
\end{tabular}

Data are shown as mean \pm standard deviation, $\mathrm{n}(\%)$, or median (range). 
AECOPD, acute exacerbation of chronic obstructive pulmonary disease; GOLD, Global Initiative for Obstructive Lung Disease; NA, not available; $\mathrm{PH}-\mathrm{CL}$, phlegm-heat congesting lung; $\mathrm{PH}-\mathrm{AL}$, phlegm-damp amassing in the lung; SCOPD, stable chronic obstructive pulmonary disease;

Table 3. Statistical analysis of diagnostic lipid biomarkers 


\begin{tabular}{|c|c|c|c|c|c|c|c|c|}
\hline ID & Name & $\mathrm{m} / \mathrm{z}$ & $t_{R}(\min )$ & Trend & $\begin{array}{l}\text { Fold } \\
\text { change }\end{array}$ & $\begin{array}{l}\mathrm{P} \\
\text { value }\end{array}$ & FDR & VIP \\
\hline \multicolumn{9}{|l|}{ SCOPD vs Health } \\
\hline 746/783/784/832/838/841/852 & $\begin{array}{l}\text { TG } \\
\text { 16:0_17:1_22:4 } \\
\text { \& TG } \\
\text { 16:0_19:1_20:4 } \\
\text { \& TG } \\
\text { 16:0_19:2_20:3 } \\
\text { \& TG } \\
\text { 17:0_17:1_21:4 } \\
\text { \& TG } \\
\text { 17:0_18:1_20:4 } \\
\text { \& TG } \\
\text { 17:0_18:2_20:3 } \\
\text { \&:TG } \\
\text { 17:1_18:1_20:3 }\end{array}$ & 912.8001 & 14.96 & $\uparrow$ & $1.37 \mathrm{E}+00$ & $\begin{array}{l}9.39 \mathrm{E}- \\
05\end{array}$ & $\begin{array}{l}1.13 \mathrm{E}- \\
04\end{array}$ & $1.98 \mathrm{E}+00$ \\
\hline 320 & LPE 20:3 & 504.3076 & 1.83 & $\uparrow$ & $1.29 \mathrm{E}+00$ & $\begin{array}{l}3.55 \mathrm{E}- \\
06\end{array}$ & $\begin{array}{l}6.33 \mathrm{E}- \\
06\end{array}$ & 1.67E+00 \\
\hline 648/676/696/715/725 & $\begin{array}{l}\text { TG } \\
\text { 14:0_17:0_18:1 } \\
\text { \& TG } \\
\text { 15:0_16:0_18:1 } \\
\text { \& TG } \\
\text { 15:1_16:0_18:0 } \\
\text { \& TG } \\
\text { 16:0_16:0_17:1 } \\
\text { \& TG } \\
\text { 16:0_16:1_17:0 }\end{array}$ & 836.7699 & 15.62 & $\downarrow$ & 7.95E-01 & $\begin{array}{l}5.68 \mathrm{E}- \\
05\end{array}$ & $\begin{array}{l}7.26 \mathrm{E}- \\
05\end{array}$ & $1.55 \mathrm{E}+00$ \\
\hline $456 / 460$ & $\begin{array}{l}\text { PE-O } \\
\text { 18:1p_22:5-1 \& } \\
\text { PE-O } \\
18: 2 p \_22: 4\end{array}$ & 776.5571 & 9.48 & $\downarrow$ & 7.03E-01 & $\begin{array}{l}3.12 \mathrm{E}- \\
09\end{array}$ & $\begin{array}{l}1.63 \mathrm{E}- \\
08\end{array}$ & $1.51 \mathrm{E}+00$ \\
\hline $375 / 379$ & $\begin{array}{l}\text { PC 18:2_22:6 \& } \\
\text { PC 20:4_20:4 }\end{array}$ & 830.5677 & 7.49 & $\downarrow$ & $7.22 \mathrm{E}-01$ & $\begin{array}{l}1.15 \mathrm{E}- \\
09\end{array}$ & $\begin{array}{l}7.53 \mathrm{E}- \\
09\end{array}$ & $1.44 \mathrm{E}+00$ \\
\hline 649/665/677/681/697/700/726/790 & $\begin{array}{l}\text { TG } \\
\text { 14:0_17:1_18:1 } \\
\text { \& TG } \\
\text { 14:1_17:1_18:0 } \\
\text { \& TG } \\
\text { 15:0_16:0_18:2 } \\
\text { \& TG } \\
\text { 15:0_16:1_18:1 } \\
\text { \& TG } \\
\text { 15:1_16:0_18:1 } \\
\text { \& TG } \\
\text { 15:1_16:1_18:0 } \\
\text { \& TG } \\
\text { 16:0_16:1_17:1 } \\
\text { \& TG } \\
\text { 16:1_16:1_17:0 }\end{array}$ & 834.7530 & 14.84 & $\downarrow$ & 7.62E-01 & $\begin{array}{l}7.06 \mathrm{E}- \\
04\end{array}$ & $\begin{array}{l}7.71 \mathrm{E}- \\
04\end{array}$ & $1.43 \mathrm{E}+00$ \\
\hline 2 & CE 17:0 & 656.6313 & 12.64 & $\downarrow$ & 4.62E-01 & $\begin{array}{l}7.95 \mathrm{E}- \\
12\end{array}$ & $\begin{array}{l}1.89 \mathrm{E}- \\
10\end{array}$ & $1.41 \mathrm{E}+00$ \\
\hline 212 & FA 24:0 & 367.3566 & 7.55 & $\downarrow$ & 8.31E-01 & $\begin{array}{l}1.92 \mathrm{E}- \\
05\end{array}$ & $\begin{array}{l}2.70 \mathrm{E}- \\
05\end{array}$ & $1.38 \mathrm{E}+00$ \\
\hline
\end{tabular}




\begin{tabular}{|c|c|c|c|c|c|c|c|c|}
\hline ID & Name & $\mathrm{m} / \mathrm{z}$ & $t_{R}(\min )$ & Trend & $\begin{array}{l}\text { Fold } \\
\text { change }\end{array}$ & $\begin{array}{l}P \\
\text { value }\end{array}$ & FDR & VIP \\
\hline 666/678/682/698/701/708/791 & $\begin{array}{l}\text { TG } \\
\text { 14:1_17:1_18:1 } \\
\text { \& TG } \\
\text { 15:0_16:0_18:3 } \\
\text { \& TG } \\
\text { 15:0_16:1_18:2 } \\
\text { \& TG } \\
\text { 15:1_16:0_18:2 } \\
\text { \& TG } \\
\text { 15:1_16:1_18:1 } \\
\text { \& TG } \\
\text { 15:2_16:0_18:1 } \\
\text { \& TG } \\
\text { 16:1_16:1_17:1 }\end{array}$ & 832.7392 & 14.46 & $\downarrow$ & 7.34E-01 & $\begin{array}{l}2.11 \mathrm{E}- \\
04\end{array}$ & $\begin{array}{l}2.44 \mathrm{E}- \\
04\end{array}$ & $1.37 \mathrm{E}+00$ \\
\hline 685/703/744/800/801 & $\begin{array}{l}\text { TG } \\
\text { 15:0_18:1_18:2 } \\
\text { \& TG } \\
\text { 15:1_18:1_18:1 } \\
\text { \& TG } \\
\text { 16:0_17:1_18:2 } \\
\text { \& TG } \\
\text { 16:1_17:0_18:2 } \\
\text { \& TG } \\
\text { 16:1_17:1_18:1 }\end{array}$ & 860.7701 & 14.91 & $\downarrow$ & 7.83E-01 & $\begin{array}{l}6.50 \mathrm{E}- \\
06\end{array}$ & $\begin{array}{l}1.09 \mathrm{E}- \\
05\end{array}$ & $1.35 \mathrm{E}+00$ \\
\hline 392 & $\begin{array}{l}\text { PC-O } \\
16: 1 \_16: 0 p\end{array}$ & 716.5583 & 9.08 & $\uparrow$ & $1.29 \mathrm{E}+00$ & $\begin{array}{l}4.25 \mathrm{E}- \\
04\end{array}$ & $\begin{array}{l}4.78 \mathrm{E}- \\
04\end{array}$ & $1.29 \mathrm{E}+00$ \\
\hline 667/683/684/702/709/799/828 & $\begin{array}{l}\text { TG } \\
\text { 14:1_17:2_18:1 } \\
\text { \& TG } \\
\text { 15:0_16:1_18:3 } \\
\text { \& TG } \\
\text { 15:0_16:2_18:2 } \\
\text { \& TG } \\
\text { 15:1_16:2_18:1 } \\
\text { \& TG } \\
\text { 15:2_17:1_17:1 } \\
\text { \& TG } \\
\text { 16:1_16:2_17:1 } \\
\text { \& TG } \\
\text { 16:2_16:2_17:0 }\end{array}$ & 830.7240 & 14.45 & $\downarrow$ & $6.62 \mathrm{E}-01$ & $\begin{array}{l}2.83 \mathrm{E}- \\
05\end{array}$ & $\begin{array}{l}3.86 \mathrm{E}- \\
05\end{array}$ & $1.28 \mathrm{E}+00$ \\
\hline $599 / 600 / 601 / 624$ & $\begin{array}{l}\text { TG } \\
\text { 10:0_16:0_18:2 } \\
\text { \& TG } \\
\text { 10:0_16:1_18:1 } \\
\text { \& TG } \\
\text { 10:1_16:0_18:1 } \\
\text { \& TG } \\
\text { 14:0_12:0_18:2 }\end{array}$ & 764.6761 & 13.65 & $\downarrow$ & $3.76 \mathrm{E}-01$ & $\begin{array}{l}4.87 \mathrm{E}- \\
04\end{array}$ & $\begin{array}{l}5.41 \mathrm{E}- \\
04\end{array}$ & $1.28 \mathrm{E}+00$ \\
\hline 686/688/704/747/802/806/829 & $\begin{array}{l}\text { TG } \\
\text { 15:0_18:1_18:3 } \\
\text { \& TG } \\
\text { 15:0_18:2_18:2 } \\
\text { \& TG } \\
\text { 15:1_18:1_18:2 } \\
\text { \& TG } \\
\text { 16:0_17:2_18:2 } \\
\text { \& TG } \\
\text { 16:1_17:1_18:2 } \\
\text { \& TG } \\
\text { 16:1_17:2_18:1 } \\
\text { \& TG } \\
\text { 16:2_17:1_18:1 }\end{array}$ & 858.7551 & 14.50 & $\downarrow$ & $8.26 \mathrm{E}-01$ & $\begin{array}{l}1.05 \mathrm{E}- \\
06\end{array}$ & $\begin{array}{l}2.19 \mathrm{E}- \\
06\end{array}$ & $1.23 \mathrm{E}+00$ \\
\hline 344 & PC 16:0_22:6 & 806.5714 & 8.22 & $\downarrow$ & 8.33E-01 & $\begin{array}{l}1.64 \mathrm{E}- \\
12\end{array}$ & $\begin{array}{l}7.18 \mathrm{E}- \\
11\end{array}$ & $1.22 \mathrm{E}+00$ \\
\hline
\end{tabular}




\begin{tabular}{|c|c|c|c|c|c|c|c|c|}
\hline ID & Name & $\mathrm{m} / \mathrm{z}$ & $t_{R}(\min )$ & Trend & $\begin{array}{l}\text { Fold } \\
\text { change }\end{array}$ & $\begin{array}{l}P \\
\text { value }\end{array}$ & FDR & VIP \\
\hline $563 / 580$ & $\begin{array}{l}\text { SM d18:1_18:2 } \\
\text { \& SM } \\
\text { d18:2_18:1 }\end{array}$ & 727.5751 & 7.42 & $\downarrow$ & $7.50 \mathrm{E}-01$ & $\begin{array}{l}1.36 \mathrm{E}- \\
03\end{array}$ & $\begin{array}{l}2.37 \mathrm{E}- \\
03\end{array}$ & $1.72 \mathrm{E}+00$ \\
\hline $638 / 674 / 711$ & $\begin{array}{l}\text { TG } \\
\text { 14:0_16:0_18:0 } \\
\text { \& TG } \\
\text { 15:0_16:0_17:0 } \\
\text { \& TG } \\
\text { 16:0_16:0_16:0 }\end{array}$ & 824.7705 & 15.44 & $\downarrow$ & 8.13E-01 & $\begin{array}{l}6.84 \mathrm{E}- \\
03\end{array}$ & $\begin{array}{l}9.28 \mathrm{E}- \\
03\end{array}$ & $1.60 \mathrm{E}+00$ \\
\hline $338 / 364$ & $\begin{array}{l}\text { PC 16:0_20:3 \& } \\
\text { PC 18:1_18:2 }\end{array}$ & 784.5872 & 9.07 & $\downarrow$ & 7.70E-01 & $\begin{array}{l}9.17 \mathrm{E}- \\
07\end{array}$ & $\begin{array}{l}9.24 \mathrm{E}- \\
06\end{array}$ & $1.47 \mathrm{E}+00$ \\
\hline 384 & $\begin{array}{l}\text { PC-0 } \\
\text { 16:0e_20:3 }\end{array}$ & 770.6052 & 9.59 & $\downarrow$ & $6.73 \mathrm{E}-01$ & $\begin{array}{l}1.94 \mathrm{E}- \\
04\end{array}$ & $\begin{array}{l}4.63 \mathrm{E}- \\
04\end{array}$ & $1.41 \mathrm{E}+00$ \\
\hline 392 & $\begin{array}{l}\text { PC-0 } \\
\text { 16:1_16:0p }\end{array}$ & 716.5583 & 9.08 & $\downarrow$ & $6.93 \mathrm{E}-01$ & $\begin{array}{l}1.06 \mathrm{E}- \\
02\end{array}$ & $\begin{array}{l}1.35 \mathrm{E}- \\
02\end{array}$ & $1.40 \mathrm{E}+00$ \\
\hline 207 & DG 20:4_20:4 & 682.5405 & 9.58 & $\downarrow$ & $5.62 \mathrm{E}-01$ & $\begin{array}{l}5.53 \mathrm{E}- \\
06\end{array}$ & $\begin{array}{l}3.22 \mathrm{E}- \\
05\end{array}$ & $1.39 \mathrm{E}+00$ \\
\hline 645/659/719/730/736/737/793 & $\begin{array}{l}\text { TG } \\
\text { 14:0_16:1_20:3 } \\
\text { \& TG } \\
\text { 14:1_16:0_20:3 } \\
\text { \& TG } \\
\text { 16:0_16:0_18:4 } \\
\text { \& TG } \\
\text { 16:0_16:1_18:3 } \\
\text { \& TG } \\
\text { 16:0_16:2_18:2 } \\
\text { \& TG } \\
\text { 16:0_16:3_18:1 } \\
\text { \& TG } \\
\text { 16:1_16:1_18:2 }\end{array}$ & 844.7390 & 14.24 & $\downarrow$ & $7.58 \mathrm{E}-01$ & $\begin{array}{l}2.66 \mathrm{E}- \\
03\end{array}$ & $\begin{array}{l}4.16 \mathrm{E}- \\
03\end{array}$ & $1.36 \mathrm{E}+00$ \\
\hline 722/740/750 & $\begin{array}{l}\text { TG } \\
\text { 16:0_16:0_20:1 } \\
\text { \& TG } \\
\text { 16:0_17:0_19:1 } \\
\text { \& TG } \\
\text { 16:0_18:0_18:1- } \\
2\end{array}$ & 878.8050 & 15.87 & $\downarrow$ & 8.32E-01 & $\begin{array}{l}2.31 \mathrm{E}- \\
05\end{array}$ & $\begin{array}{l}8.91 \mathrm{E}- \\
05\end{array}$ & $1.34 \mathrm{E}+00$ \\
\hline 749 & $\begin{array}{l}\text { TG } \\
16: 0 \_18: 0 \_18: 1- \\
1\end{array}$ & 878.8050 & 15.47 & $\downarrow$ & 8.31E-01 & $\begin{array}{l}2.31 \mathrm{E}- \\
05\end{array}$ & $\begin{array}{l}8.91 \mathrm{E}- \\
05\end{array}$ & $1.33 \mathrm{E}+00$ \\
\hline 374 & PC 18:2_20:5 & 804.5529 & 6.96 & $\downarrow$ & 5.83E-01 & $\begin{array}{l}9.39 \mathrm{E}- \\
04\end{array}$ & $\begin{array}{l}1.73 \mathrm{E}- \\
03\end{array}$ & $1.33 \mathrm{E}+00$ \\
\hline 650/728/735/792 & $\begin{array}{l}\text { TG } \\
\text { 14:0_18:1_18:2 } \\
\text { \& TG } \\
\text { 16:0_16:1_18:2- } \\
\text { 1 \& TG } \\
\text { 16:0_16:2_18:1 } \\
\text { \& TG } \\
\text { 16:1_16:1_18:1 }\end{array}$ & 846.7540 & 14.66 & $\downarrow$ & 7.73E-01 & $\begin{array}{l}1.65 \mathrm{E}- \\
04\end{array}$ & $\begin{array}{l}4.23 \mathrm{E}- \\
04\end{array}$ & $1.33 \mathrm{E}+00$ \\
\hline 751/807/758 & $\begin{array}{l}\text { TG } \\
\text { 16:0_18:0_18:2 } \\
\text { \& TG } \\
\text { 16:1_18:0_18:1 } \\
\text { \& TG } \\
\text { 16:0_18:1_18:1 }\end{array}$ & 876.7988 & 15.47 & $\downarrow$ & 8.27E-01 & $\begin{array}{l}4.56 \mathrm{E}- \\
05\end{array}$ & $\begin{array}{l}1.57 \mathrm{E}- \\
04\end{array}$ & $1.31 \mathrm{E}+00$ \\
\hline 357 & PC 18:0_20:3 & 812.6151 & 9.97 & $\downarrow$ & 7.26E-01 & $\begin{array}{l}1.84 \mathrm{E}- \\
05\end{array}$ & $\begin{array}{l}7.79 \mathrm{E}- \\
05\end{array}$ & $1.31 \mathrm{E}+00$ \\
\hline
\end{tabular}




\begin{tabular}{|c|c|c|c|c|c|c|c|c|}
\hline ID & Name & $\mathrm{m} / \mathrm{z}$ & $t_{R}(\min )$ & Trend & $\begin{array}{l}\text { Fold } \\
\text { change }\end{array}$ & $\begin{array}{l}\mathrm{P} \\
\text { value }\end{array}$ & FDR & VIP \\
\hline $574 / 590 / 595$ & $\begin{array}{l}\text { SM d18:1_25:1 } \\
\text { \& SM } \\
\text { d18:2_25:0 \& } \\
\text { SM d19:1_24:2 }\end{array}$ & 827.7010 & 11.50 & $\uparrow$ & $1.24 \mathrm{E}+00$ & $\begin{array}{l}1.94 \mathrm{E}- \\
04\end{array}$ & $\begin{array}{l}4.63 \mathrm{E}- \\
04\end{array}$ & $1.29 \mathrm{E}+00$ \\
\hline 718/727/743 & $\begin{array}{l}\text { TG } \\
\text { 16:0_16:0_18:2 } \\
\text { \& TG } \\
\text { 16:0_16:1_18:1 } \\
\text { \& TG } \\
\text { 16:0_17:1_17:1 }\end{array}$ & 848.7717 & 15.06 & $\downarrow$ & 7.81E-01 & $\begin{array}{l}5.38 \mathrm{E}- \\
04\end{array}$ & $\begin{array}{l}1.08 \mathrm{E}- \\
03\end{array}$ & $1.29 \mathrm{E}+00$ \\
\hline 144 & DG 16:0_16:1 & 584.5241 & 10.50 & $\downarrow$ & 7.41E-01 & $\begin{array}{l}1.06 \mathrm{E}- \\
02\end{array}$ & $\begin{array}{l}1.35 \mathrm{E}- \\
02\end{array}$ & $1.28 \mathrm{E}+00$ \\
\hline 461 & $\begin{array}{l}\text { PE-O } \\
\text { 18:2p_22:6 }\end{array}$ & 772.5268 & 8.29 & $\downarrow$ & 7.55E-01 & $\begin{array}{l}4.44 \mathrm{E}- \\
03\end{array}$ & $\begin{array}{l}6.29 \mathrm{E}- \\
03\end{array}$ & $1.25 \mathrm{E}+00$ \\
\hline 717 & $\begin{array}{l}\text { TG } \\
\text { 16:0_16:0_18:1 }\end{array}$ & 850.7860 & 15.44 & $\downarrow$ & 7.60E-01 & $\begin{array}{l}9.39 \mathrm{E}- \\
04\end{array}$ & $\begin{array}{l}1.73 \mathrm{E}- \\
03\end{array}$ & $1.23 \mathrm{E}+00$ \\
\hline $52 / 83 / 108$ & $\begin{array}{l}\text { Cer d17:1_21:1 } \\
\text { \& Cer } \\
\text { d18:1_20:1 \& } \\
\text { Cer d18:2_20:0 }\end{array}$ & 592.5660 & 10.77 & $\downarrow$ & 7.48E-01 & $\begin{array}{l}2.49 \mathrm{E}- \\
04\end{array}$ & $\begin{array}{l}5.63 \mathrm{E}- \\
04\end{array}$ & $1.22 \mathrm{E}+00$ \\
\hline 383 & $\begin{array}{l}\text { PC-O } \\
\text { 16:0_16:0p }\end{array}$ & 718.5738 & 9.84 & $\downarrow$ & 7.95E-01 & $\begin{array}{l}1.36 \mathrm{E}- \\
03\end{array}$ & $\begin{array}{l}2.37 \mathrm{E}- \\
03\end{array}$ & $1.22 \mathrm{E}+00$ \\
\hline 373 & PC 18:2_20:4 & 806.5714 & 7.89 & $\downarrow$ & 7.51E-01 & $\begin{array}{l}4.07 \mathrm{E}- \\
07\end{array}$ & $\begin{array}{l}5.55 \mathrm{E}- \\
06\end{array}$ & $1.20 \mathrm{E}+00$ \\
\hline \multicolumn{9}{|l|}{ PH-CL-AECOPD vs SCOPD } \\
\hline 395 & $\begin{array}{l}\text { PC-O } \\
\text { 16:1e_22:5-2 }\end{array}$ & 792.5890 & 9.75 & $\downarrow$ & 3.94E-01 & $\begin{array}{l}8.39 \mathrm{E}- \\
06\end{array}$ & $\begin{array}{l}1.13 \mathrm{E}- \\
05\end{array}$ & $2.04 \mathrm{E}+00$ \\
\hline 603/605/611/613/618/631 & $\begin{array}{l}\text { TG } \\
\text { 12:0_15:0_18:1 } \\
\text { \& TG } \\
\text { 12:0_16:0_17:1 } \\
\text { \& TG } \\
\text { 12:1_15:0_18:0 } \\
\text { \& TG } \\
\text { 12:1_16:0_17:0 } \\
\text { \& TG } \\
\text { 13:0_15:0_17:1 } \\
\text { \& TG } \\
\text { 14:0_15:0_16:1 }\end{array}$ & 780.7075 & 14.38 & $\uparrow$ & $1.65 \mathrm{E}+00$ & $\begin{array}{l}1.81 \mathrm{E}- \\
08\end{array}$ & $\begin{array}{l}1.08 \mathrm{E}- \\
07\end{array}$ & $1.90 \mathrm{E}+00$ \\
\hline 619/622/630/672 & $\begin{array}{l}\text { TG } \\
\text { 13:0_16:0_16:0 } \\
\text { \& TG } \\
\text { 13:0_17:0_15:0 } \\
\text { \& TG } \\
\text { 14:0_15:0_16:0 } \\
\text { \& TG } \\
\text { 15:0_15:0_15:0 }\end{array}$ & 782.7231 & 14.70 & $\uparrow$ & $1.81 \mathrm{E}+00$ & $\begin{array}{l}8.38 \mathrm{E}- \\
09\end{array}$ & $\begin{array}{l}6.27 \mathrm{E}- \\
08\end{array}$ & $1.88 \mathrm{E}+00$ \\
\hline 2 & CE 17:0 & 656.6313 & 12.64 & $\downarrow$ & 4.60E-01 & $\begin{array}{l}4.98 \mathrm{E}- \\
08\end{array}$ & $\begin{array}{l}2.01 \mathrm{E}- \\
07\end{array}$ & $1.86 \mathrm{E}+00$ \\
\hline $597 / 623 / 625$ & $\begin{array}{l}\text { TG } \\
\text { 10:0_14:0_18:0 } \\
\text { \& TG } \\
\text { 14:0_12:0_16:0 } \\
\text { \& TG } \\
\text { 14:0_14:0_14:0 }\end{array}$ & 740.6764 & 14.07 & $\uparrow$ & $1.31 \mathrm{E}+00$ & $\begin{array}{l}1.50 \mathrm{E}- \\
05\end{array}$ & $\begin{array}{l}1.91 \mathrm{E}- \\
05\end{array}$ & $1.73 \mathrm{E}+00$ \\
\hline
\end{tabular}




\begin{tabular}{|c|c|c|c|c|c|c|c|c|}
\hline ID & Name & $\mathrm{m} / \mathrm{z}$ & $t_{R}(\min )$ & Trend & $\begin{array}{l}\text { Fold } \\
\text { change }\end{array}$ & $\begin{array}{l}P \\
\text { value }\end{array}$ & FDR & VIP \\
\hline 633/637/673 & $\begin{array}{l}\text { TG } \\
\text { 14:0_15:0_18:0 } \\
\text { \& TG } \\
\text { 14:0_16:0_17:0 } \\
\text { \& TG } \\
\text { 15:0_16:0_16:0 }\end{array}$ & 810.7511 & 15.22 & $\uparrow$ & $1.62 \mathrm{E}+00$ & $\begin{array}{l}9.00 \mathrm{E}- \\
10\end{array}$ & $\begin{array}{l}1.31 \mathrm{E}- \\
08\end{array}$ & $1.58 \mathrm{E}+00$ \\
\hline 604/616/617/629/635 & $\begin{array}{l}\text { TG } \\
\text { 12:0_16:0_16:0 } \\
\text { \& TG } \\
\text { 13:0_13:0_18:0 } \\
\text { \& TG } \\
\text { 13:0_15:0_16:0 } \\
\text { \& TG } \\
\text { 14:0_15:0_15:0 } \\
\text { \& TG } \\
\text { 14:0_16:0_16:0 }\end{array}$ & 768.7078 & 14.53 & $\uparrow$ & $1.34 \mathrm{E}+00$ & $\begin{array}{l}2.16 \mathrm{E}- \\
05\end{array}$ & $\begin{array}{l}2.63 \mathrm{E}- \\
05\end{array}$ & $1.57 \mathrm{E}+00$ \\
\hline $598 / 602 / 612 / 626$ & $\begin{array}{l}\text { TG } \\
\text { 10:0_16:0_18:1 } \\
\text { \& TG } \\
\text { 12:0_14:0_18:1 } \\
\text { \& TG } \\
\text { 12:1_16:0_16:0 } \\
\text { \&TG } \\
\text { 14:0_14:0_16:1 }\end{array}$ & 766.6918 & 14.12 & $\uparrow$ & $1.42 \mathrm{E}+00$ & $\begin{array}{l}7.56 \mathrm{E}- \\
04\end{array}$ & $\begin{array}{l}7.67 \mathrm{E}- \\
04\end{array}$ & $1.56 \mathrm{E}+00$ \\
\hline 148 & DG 16:0_18:0 & 614.5720 & 11.95 & $\uparrow$ & $1.57 \mathrm{E}+00$ & $\begin{array}{l}3.83 \mathrm{E}- \\
08\end{array}$ & $\begin{array}{l}1.65 \mathrm{E}- \\
07\end{array}$ & $1.49 \mathrm{E}+00$ \\
\hline 143 & DG 16:0_16:0 & 586.5404 & 11.15 & $\uparrow$ & $1.57 \mathrm{E}+00$ & $\begin{array}{l}3.83 \mathrm{E}- \\
08\end{array}$ & $\begin{array}{l}1.65 \mathrm{E}- \\
07\end{array}$ & $1.46 \mathrm{E}+00$ \\
\hline 169 & DG 18:0_20:0 & 670.6351 & 13.23 & $\uparrow$ & $1.54 \mathrm{E}+00$ & $\begin{array}{l}3.29 \mathrm{E}- \\
07\end{array}$ & $\begin{array}{l}8.37 \mathrm{E}- \\
07\end{array}$ & $1.41 \mathrm{E}+00$ \\
\hline 384 & $\begin{array}{l}\text { PC-O } \\
\text { 16:0e_20:3 }\end{array}$ & 770.6052 & 9.59 & $\downarrow$ & 4.97E-01 & $\begin{array}{l}3.36 \mathrm{E}- \\
06\end{array}$ & $\begin{array}{l}5.34 \mathrm{E}- \\
06\end{array}$ & $1.40 \mathrm{E}+00$ \\
\hline 663/699/707 & $\begin{array}{l}\text { TG } \\
\text { 14:1_16:1_17:1 } \\
\text { \& TG } \\
\text { 15:1_16:1_16:1 } \\
\text { \& TG } \\
\text { 15:2_16:0_16:1 }\end{array}$ & 804.7064 & 14.44 & $\uparrow$ & $1.35 \mathrm{E}+00$ & $\begin{array}{l}9.68 \mathrm{E}- \\
05\end{array}$ & $\begin{array}{l}1.05 \mathrm{E}- \\
04\end{array}$ & 1.37E+00 \\
\hline 596 & $\begin{array}{l}\text { TG } \\
10: 0 \_14: 0 \_16: 0\end{array}$ & 712.6452 & 13.54 & $\uparrow$ & $1.34 \mathrm{E}+00$ & $\begin{array}{l}1.15 \mathrm{E}- \\
04\end{array}$ & $\begin{array}{l}1.21 \mathrm{E}- \\
04\end{array}$ & 1.37E+00 \\
\hline 254 & LPC 16:2 & 492.3085 & 1.60 & $\downarrow$ & $6.22 \mathrm{E}-01$ & $\begin{array}{l}7.99 \mathrm{E}- \\
08\end{array}$ & $\begin{array}{l}2.79 \mathrm{E}- \\
07\end{array}$ & $1.33 \mathrm{E}+00$ \\
\hline 444 & $\begin{array}{l}\text { PE-O } \\
\text { 18:0p_20:5 }\end{array}$ & 750.5435 & 9.74 & $\downarrow$ & $3.66 \mathrm{E}-01$ & $\begin{array}{l}6.69 \mathrm{E}- \\
05\end{array}$ & $\begin{array}{l}7.60 \mathrm{E}- \\
05\end{array}$ & $1.29 \mathrm{E}+00$ \\
\hline 383 & $\begin{array}{l}\text { PC-0 } \\
\text { 16:0_16:0p }\end{array}$ & 718.5738 & 9.84 & $\downarrow$ & 7.04E-01 & $\begin{array}{l}1.27 \mathrm{E}- \\
06\end{array}$ & $\begin{array}{l}2.21 \mathrm{E}- \\
06\end{array}$ & $1.28 \mathrm{E}+00$ \\
\hline 451 & $\begin{array}{l}\text { PE-O } \\
\text { 18:1p_18:2 }\end{array}$ & 726.5427 & 9.80 & $\downarrow$ & $5.90 \mathrm{E}-01$ & $\begin{array}{l}2.42 \mathrm{E}- \\
06\end{array}$ & $\begin{array}{l}3.99 \mathrm{E}- \\
06\end{array}$ & $1.26 \mathrm{E}+00$ \\
\hline $432 / 440$ & $\begin{array}{l}\text { PE-O } \\
\text { 16:0p_18:2 \& } \\
\text { PE-O } \\
\text { 16:1_18:1p }\end{array}$ & 700.5264 & 9.53 & $\downarrow$ & $6.85 \mathrm{E}-01$ & $\begin{array}{l}6.36 \mathrm{E}- \\
06\end{array}$ & $\begin{array}{l}9.10 \mathrm{E}- \\
06\end{array}$ & $1.25 \mathrm{E}+00$ \\
\hline $149 / 157$ & $\begin{array}{l}\text { DG 16:0_18:1 \& } \\
\text { DG 16:1_18:0 }\end{array}$ & 612.5565 & 11.26 & $\downarrow$ & $5.26 \mathrm{E}-01$ & $\begin{array}{l}3.83 \mathrm{E}- \\
08\end{array}$ & $\begin{array}{l}1.65 \mathrm{E}- \\
07\end{array}$ & $1.24 \mathrm{E}+00$ \\
\hline $152 / 165$ & $\begin{array}{l}\text { DG 16:0_20:0 \& } \\
\text { DG 18:0_18:0 }\end{array}$ & 642.6050 & 12.62 & $\uparrow$ & $1.46 \mathrm{E}+00$ & $\begin{array}{l}6.51 \mathrm{E}- \\
07\end{array}$ & $\begin{array}{l}1.33 \mathrm{E}- \\
06\end{array}$ & $1.23 \mathrm{E}+00$ \\
\hline
\end{tabular}

PH-AL-AECOPD vs SCOPD

Page 17/25 


\begin{tabular}{|c|c|c|c|c|c|c|c|c|}
\hline ID & Name & $\mathrm{m} / \mathrm{z}$ & $t_{R}(\min )$ & Trend & $\begin{array}{l}\text { Fold } \\
\text { change }\end{array}$ & $\begin{array}{l}P \\
\text { value }\end{array}$ & FDR & VIP \\
\hline 395 & $\begin{array}{l}\text { PC-O } \\
\text { 16:1e_22:5-2 }\end{array}$ & 792.5890 & 9.75 & $\uparrow$ & $1.50 \mathrm{E}+00$ & $\begin{array}{l}1.34 \mathrm{E}- \\
11\end{array}$ & $\begin{array}{l}4.66 \mathrm{E}- \\
10\end{array}$ & $1.80 \mathrm{E}+00$ \\
\hline 148 & DG 16:0_18:0 & 614.5720 & 11.95 & $\downarrow$ & 2.80E-01 & $\begin{array}{l}2.58 \mathrm{E}- \\
03\end{array}$ & $\begin{array}{l}2.65 \mathrm{E}- \\
03\end{array}$ & $1.78 \mathrm{E}+00$ \\
\hline 143 & DG 16:0_16:0 & 586.5404 & 11.15 & $\downarrow$ & 2.63E-01 & $\begin{array}{l}2.58 \mathrm{E}- \\
03\end{array}$ & $\begin{array}{l}2.65 \mathrm{E}- \\
03\end{array}$ & $1.76 \mathrm{E}+00$ \\
\hline 312 & LPE 16:0 & 454.2922 & 1.92 & $\uparrow$ & $1.21 \mathrm{E}+00$ & $\begin{array}{l}2.21 \mathrm{E}- \\
09\end{array}$ & $\begin{array}{l}2.63 \mathrm{E}- \\
08\end{array}$ & $1.76 \mathrm{E}+00$ \\
\hline 315 & LPE 18:0 & 482.3237 & 2.57 & $\uparrow$ & $1.23 \mathrm{E}+00$ & $\begin{array}{l}5.13 \mathrm{E}- \\
13\end{array}$ & $\begin{array}{l}4.48 \mathrm{E}- \\
11\end{array}$ & $1.76 \mathrm{E}+00$ \\
\hline $152 / 165$ & $\begin{array}{l}\text { DG 16:0_20:0 \& } \\
\text { DG 18:0_18:0 }\end{array}$ & 642.6050 & 12.62 & $\downarrow$ & 2.90E-01 & $\begin{array}{l}2.58 \mathrm{E}- \\
03\end{array}$ & $\begin{array}{l}2.65 \mathrm{E}- \\
03\end{array}$ & $1.75 \mathrm{E}+00$ \\
\hline 309 & LPC-0 20:1p-3 & 534.3911 & 2.80 & $\uparrow$ & $1.36 \mathrm{E}+00$ & $\begin{array}{l}5.55 \mathrm{E}- \\
08\end{array}$ & $\begin{array}{l}2.11 \mathrm{E}- \\
07\end{array}$ & $1.75 \mathrm{E}+00$ \\
\hline 316 & LPE 18:1 & 480.3083 & 2.06 & $\uparrow$ & $1.31 \mathrm{E}+00$ & $\begin{array}{l}1.03 \mathrm{E}- \\
06\end{array}$ & $\begin{array}{l}2.04 \mathrm{E}- \\
06\end{array}$ & $1.65 \mathrm{E}+00$ \\
\hline 169 & DG 18:0_20:0 & 670.6351 & 13.23 & $\downarrow$ & 2.86E-01 & $\begin{array}{l}2.58 \mathrm{E}- \\
03\end{array}$ & $\begin{array}{l}2.65 \mathrm{E}- \\
03\end{array}$ & $1.56 \mathrm{E}+00$ \\
\hline $557 / 570 / 585$ & $\begin{array}{l}\text { SM d17:1_24:1 } \\
\text { \& SM } \\
\text { d18:1_23:1 \& } \\
\text { SM d18:2_23:0 }\end{array}$ & 799.6686 & 10.98 & $\uparrow$ & $1.25 \mathrm{E}+00$ & $\begin{array}{l}2.21 \mathrm{E}- \\
09\end{array}$ & $\begin{array}{l}2.63 \mathrm{E}- \\
08\end{array}$ & $1.53 \mathrm{E}+00$ \\
\hline 638/674/711 & $\begin{array}{l}\text { TG } \\
\text { 14:0_16:0_18:0 } \\
\text { \& TG } \\
\text { 15:0_16:0_17:0 } \\
\text { \& TG } \\
\text { 16:0_16:0_16:0 }\end{array}$ & 824.7705 & 15.44 & $\downarrow$ & 7.94E-01 & $\begin{array}{l}2.68 \mathrm{E}- \\
05\end{array}$ & $\begin{array}{l}3.51 \mathrm{E}- \\
05\end{array}$ & $1.45 \mathrm{E}+00$ \\
\hline 62/97/118 & $\begin{array}{l}\text { Cer d17:1_25:3 } \\
\text { \& Cer } \\
\text { d18:1_24:3 \& } \\
\text { Cer d18:2_24:2 }\end{array}$ & 644.5974 & 10.85 & $\downarrow$ & $6.56 \mathrm{E}-01$ & $\begin{array}{l}8.38 \mathrm{E}- \\
05\end{array}$ & $\begin{array}{l}1.01 \mathrm{E}- \\
04\end{array}$ & $1.32 \mathrm{E}+00$ \\
\hline 717 & $\begin{array}{l}\text { TG } \\
16: 0 \_16: 0 \_18: 1\end{array}$ & 850.7860 & 15.44 & $\downarrow$ & $8.11 \mathrm{E}-01$ & $\begin{array}{l}4.22 \mathrm{E}- \\
06\end{array}$ & $\begin{array}{l}6.58 \mathrm{E}- \\
06\end{array}$ & $1.30 \mathrm{E}+00$ \\
\hline 639/680/712 & $\begin{array}{l}\text { TG } \\
\text { 14:0_16:0_18:1 } \\
\text { \& TG } \\
\text { 15:0_16:1_17:0 } \\
\text { \& TG } \\
\text { 16:0_16:0_16:1 }\end{array}$ & 822.7546 & 15.03 & $\downarrow$ & 7.24E-01 & $\begin{array}{l}1.44 \mathrm{E}- \\
04\end{array}$ & $\begin{array}{l}1.68 \mathrm{E}- \\
04\end{array}$ & $1.30 \mathrm{E}+00$ \\
\hline 318 & LPE 20:1 & 508.3398 & 2.63 & $\uparrow$ & $1.24 \mathrm{E}+00$ & $\begin{array}{l}1.15 \mathrm{E}- \\
08\end{array}$ & $\begin{array}{l}7.54 \mathrm{E}- \\
08\end{array}$ & $1.30 \mathrm{E}+00$ \\
\hline 491 & PG 18:2_18:2-2 & 769.5040 & 6.32 & $\downarrow$ & $6.44 \mathrm{E}-01$ & $\begin{array}{l}2.43 \mathrm{E}- \\
04\end{array}$ & $\begin{array}{l}2.77 \mathrm{E}- \\
04\end{array}$ & $1.28 \mathrm{E}+00$ \\
\hline 265 & LPC 19:0-1 & 538.3868 & 2.65 & $\downarrow$ & $5.45 \mathrm{E}-01$ & $\begin{array}{l}2.43 \mathrm{E}- \\
04\end{array}$ & $\begin{array}{l}2.77 \mathrm{E}- \\
04\end{array}$ & $1.22 \mathrm{E}+00$ \\
\hline $574 / 590 / 595$ & $\begin{array}{l}\text { SM d18:1_25:1 } \\
\text { \& SM } \\
\text { d18:2_25:0 \& } \\
\text { SM d19:1_24:2 }\end{array}$ & 827.7010 & 11.50 & $\uparrow$ & $1.46 \mathrm{E}+00$ & $\begin{array}{l}2.97 \mathrm{E}- \\
06\end{array}$ & $\begin{array}{l}4.86 \mathrm{E}- \\
06\end{array}$ & $1.21 \mathrm{E}+00$ \\
\hline
\end{tabular}




\begin{tabular}{|c|c|c|c|c|c|c|c|c|}
\hline ID & Name & $\mathrm{m} / \mathrm{z}$ & $t_{R}(\min )$ & Trend & $\begin{array}{l}\text { Fold } \\
\text { change }\end{array}$ & $\begin{array}{l}P \\
\text { value }\end{array}$ & FDR & VIP \\
\hline $650 / 728 / 735 / 792$ & $\begin{array}{l}\text { TG } \\
\text { 14:0_18:1_18:2 } \\
\text { \& TG } \\
\text { 16:0_16:1_18:2- } \\
\text { 1 \& TG } \\
\text { 16:0_16:2_18:1 } \\
\text { \& TG } \\
\text { 16:1_16:1_18:1 }\end{array}$ & 846.7540 & 14.66 & $\downarrow$ & 8.33E-01 & $\begin{array}{l}1.03 \mathrm{E}- \\
06\end{array}$ & $\begin{array}{l}2.04 \mathrm{E}- \\
06\end{array}$ & $1.20 \mathrm{E}+00$ \\
\hline $620 / 632$ & $\begin{array}{l}\text { TG } \\
\text { 13:0_16:0_17:0 } \\
\text { \& TG } \\
\text { 14:0_15:0_17:0 }\end{array}$ & 796.7361 & 14.98 & $\downarrow$ & $6.90 \mathrm{E}-01$ & $\begin{array}{l}9.30 \mathrm{E}- \\
04\end{array}$ & $\begin{array}{l}1.01 \mathrm{E}- \\
03\end{array}$ & $1.20 \mathrm{E}+00$ \\
\hline
\end{tabular}

AECOPD, acute exacerbation of chronic obstructive pulmonary disease; $C E$, cholesterol ester; DG, diacylglycerol; FDR, false discovery rate; Health, healthy subjects; LPE, lyso-phosphatidylethanolamine; m/z, mass-to-charge ratio; PC-0, alkyl- and alkenyl-substituted phosphatidylcholine; $\mathrm{PE}-\mathrm{O}$, alkyl- and alkenyl-substituted phosphatidylethanolamine; $\mathrm{PH}-\mathrm{CL}$, phlegm-heat congesting lung; $\mathrm{PH}-\mathrm{AL}$, phlegmdamp amassing in the lung; SCOPD, stable chronic obstructive pulmonary disease; SM, sphingomyelin; TG, triacylglycerol; $t_{R}$ retention time; VIP, variable importance in projection

\section{Figures}

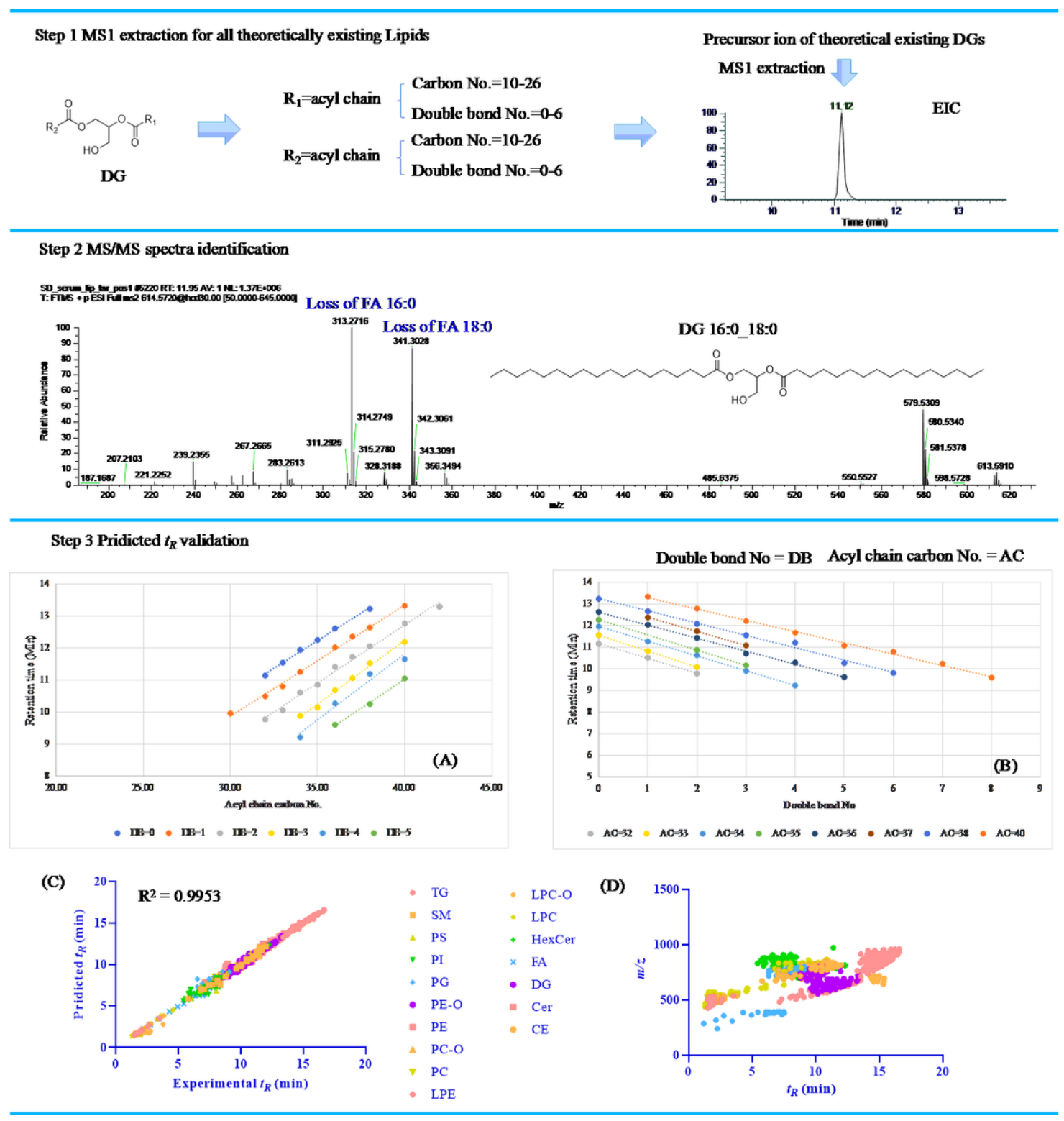

Page $19 / 25$ 
Figure 1

(A) Protocol for lipidomic profiling by UHPLC-Q-orbitrap-MS. (B) Linear relationship between tR and number of acyl carbons (Step 3A) or number of acyl double bonds (Step 3B). (C) Experimental and predicted tR of DGs. (D) The $\mathrm{m} / \mathrm{z}$ and tR of all identified lipids from mixed human serum. AC, number of acyl chain carbons; DB, number of double bonds; DG, diacylglycerol; EIC, extract ion chromatogram; FA, fatty acid; MS, mass spectrometry; MS/MS, tandem mass spectrometry; $t R$, retention time.

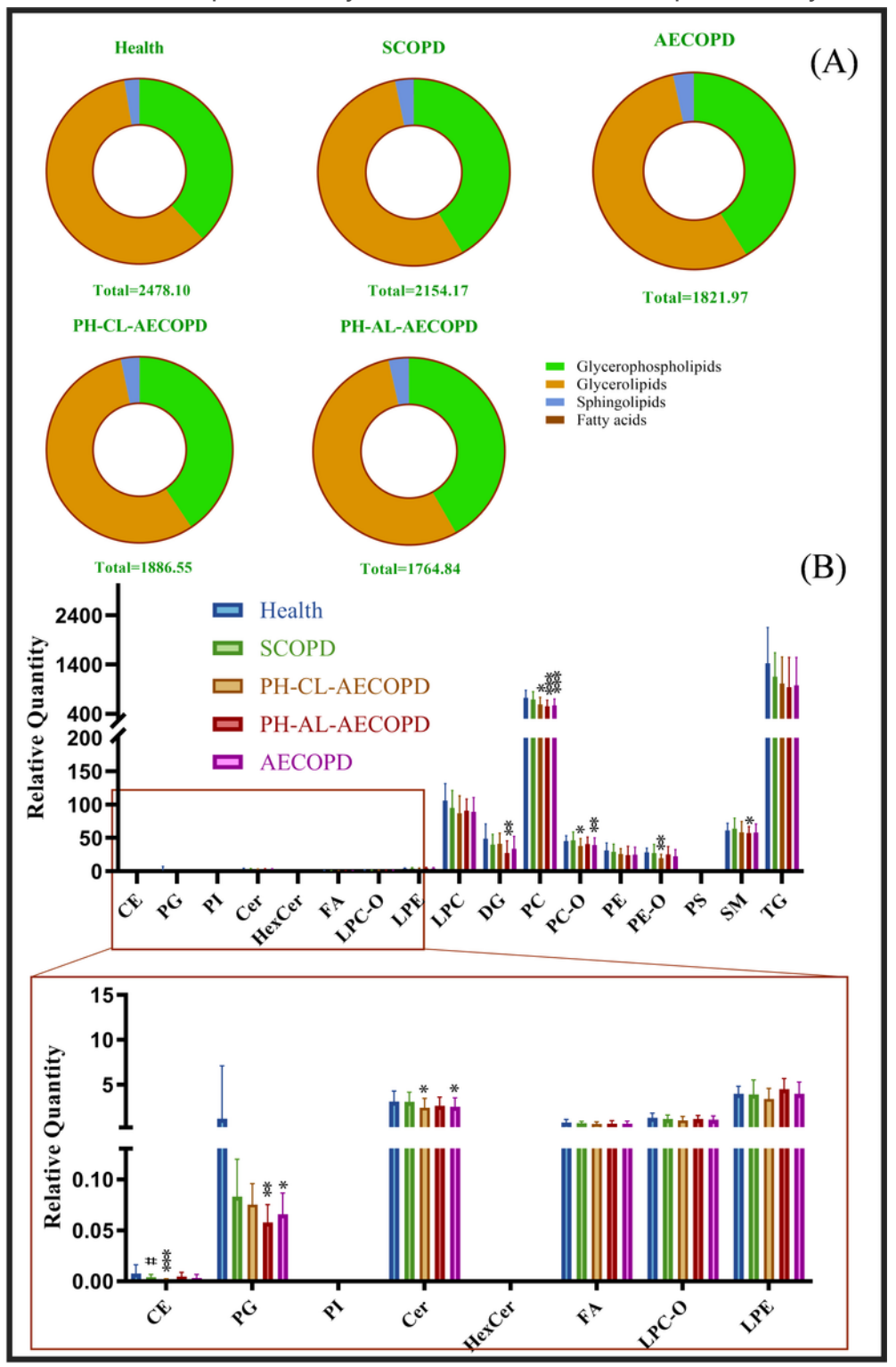

Figure 2

(A, B) Lipid distribution pie charts (A) and relative quantity of each lipid subclass (B) in healthy subjects, SCOPD patients, and PH-CLAECOPD and PH-AL-AECOPD patients. Relative quantities (peak area ratio vs corresponding subclass IS at the same concentration) of all identified lipid species were summed per lipid class for each individual sample. ${ }^{\star} p<0.05,{ }^{\star \star} p<0.01,{ }^{\star \star \star}{ }^{*}<0.001$ vs SCOPD group; \#p $<0.05$, $\# \# p<0.01, \# \# \# p<0.001$ vs Health group. AECOPD, acute exacerbation of chronic obstructive pulmonary disease; $C E$, cholesterol ester; Cer, ceramide; DG, diacylglycerol; FA, fatty acid; Health, healthy subjects; HexCer, hexaglycosylceramide; LPC, lyso-phosphatidylcholine; LPC-O, lyso-phosphatidylcholine with alkyl substituents; LPE, lyso-phosphatidylethanolamine; PC, phosphatidylcholine; PC-0, alkyl- and alkenylsubstituted phosphatidylcholine; PE, phosphatidylethanolamine; PE-0, alkyl- and alkenyl-substituted phosphatidylethanolamine; PG, phosphatidylglycerol; PI, phosphatidylinositol; PS, phosphatidylserine; $\mathrm{PH}-\mathrm{CL}$, phlegm-heat congesting lung; $\mathrm{PH}-\mathrm{AL}$, phlegm-damp amassing in the lung; SCOPD, stable chronic obstructive pulmonary disease; SM, sphingomyelin; TG, triacylglycerol. 


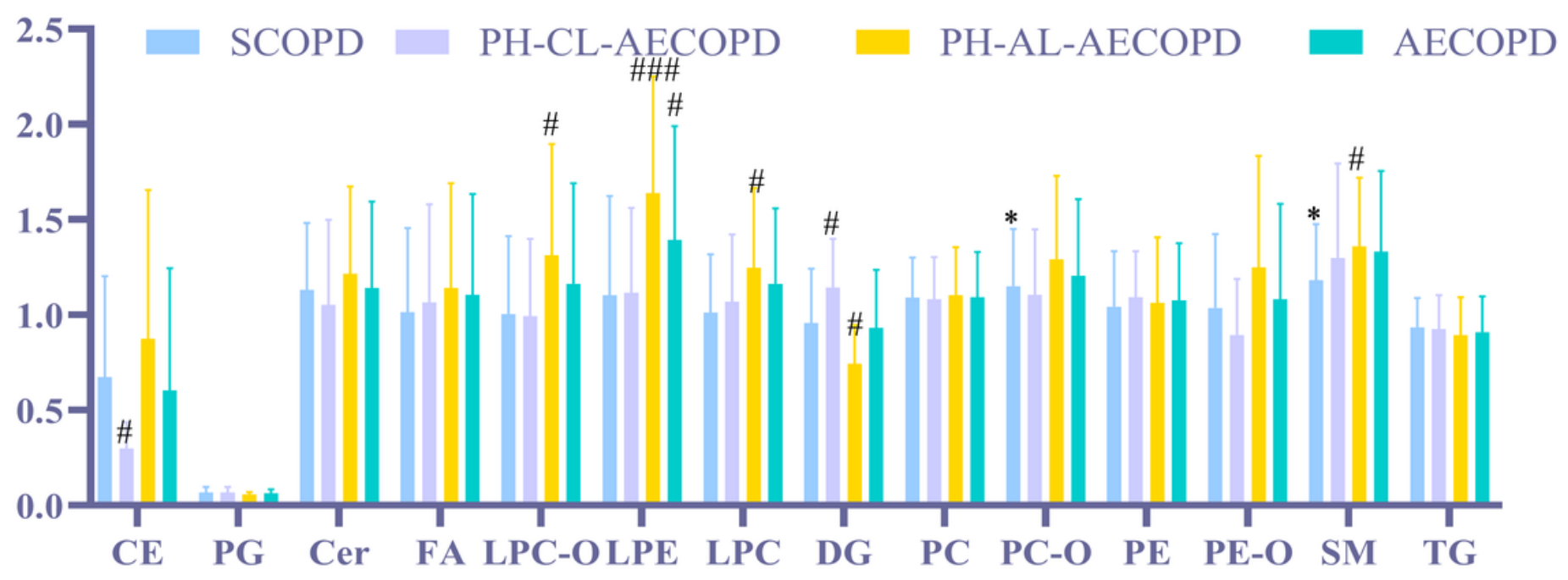

Figure 3

Percentage of each lipid subclass in total lipids. Data are expressed relative to healthy subjects. ${ }^{*}<0.05$ vs healthy subjects, \#p<0.05 vs SCOPD. AECOPD, acute exacerbation of chronic obstructive pulmonary disease; CE, cholesterol ester; Cer, ceramide; DG, diacylglycerol; FA, fatty acid; LPC, lyso-phosphatidylcholine; LPC-O, lyso-phosphatidylcholine with alkyl substituents; LPE, lyso-phosphatidylethanolamine; PC, phosphatidylcholine; PC-O, alkyl- and alkenyl-substituted phosphatidylcholine; PE, phosphatidylethanolamine; PE-0, alkyl- and alkenylsubstituted phosphatidylethanolamine; $\mathrm{PG}$, phosphatidylglycerol; $\mathrm{PH}-\mathrm{CL}$, phlegm-heat congesting lung; $\mathrm{PH}-\mathrm{AL}$, phlegm-damp amassing in the lung; SCOPD, stable chronic obstructive pulmonary disease; SM, sphingomyelin; TG, triacylglycerol. 
(A) SCOPD vs Health

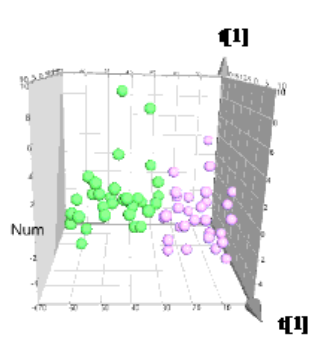

(B) AECOPD vs SCOPD

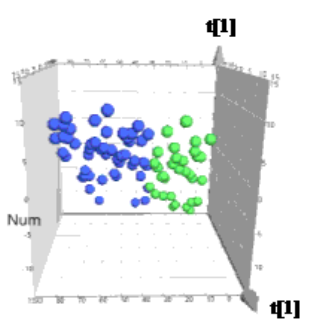

(C) PH-CL-AECOPD vs SCOPD

Heilth
SCOPD

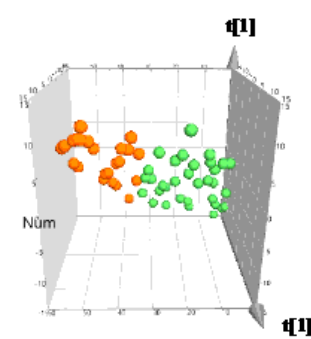

SCOPD

(D) PH-AL-AFCOPD vs SCOPD

\section{SCOPD-AECOPD}

[1]

(E)

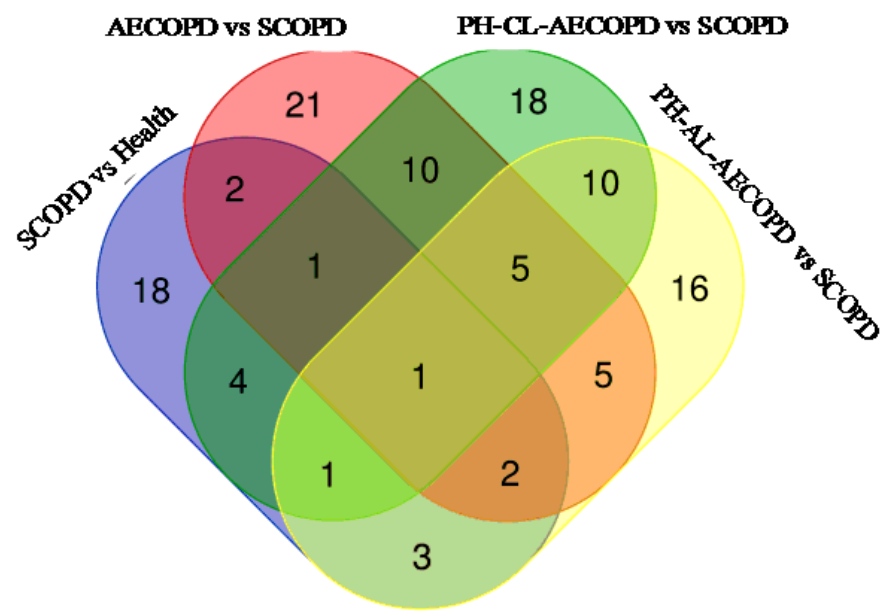

\section{Figure 4}

PLS-DA score plots for comparisons of SCOPD vs Health (A), AECOPD vs SCOPD (B), PH-CL-AECOPD vs SCOPD (C), and PH-AL-AECOPD to SCOPD (D). (E) Venn diagram of the 118 differential lipids in cross-comparisons between healthy subjects and COPD patients at different stage and of different TCM syndromes. AECOPD, acute exacerbation of chronic obstructive pulmonary disease; Health, healthy subjects; PLS-DA, projection to latent structures discriminant analysis; PH-CL, phlegm-heat congesting lung; PH-AL, phlegm-damp amassing in the lung; SCOPD, stable chronic obstructive pulmonary disease 

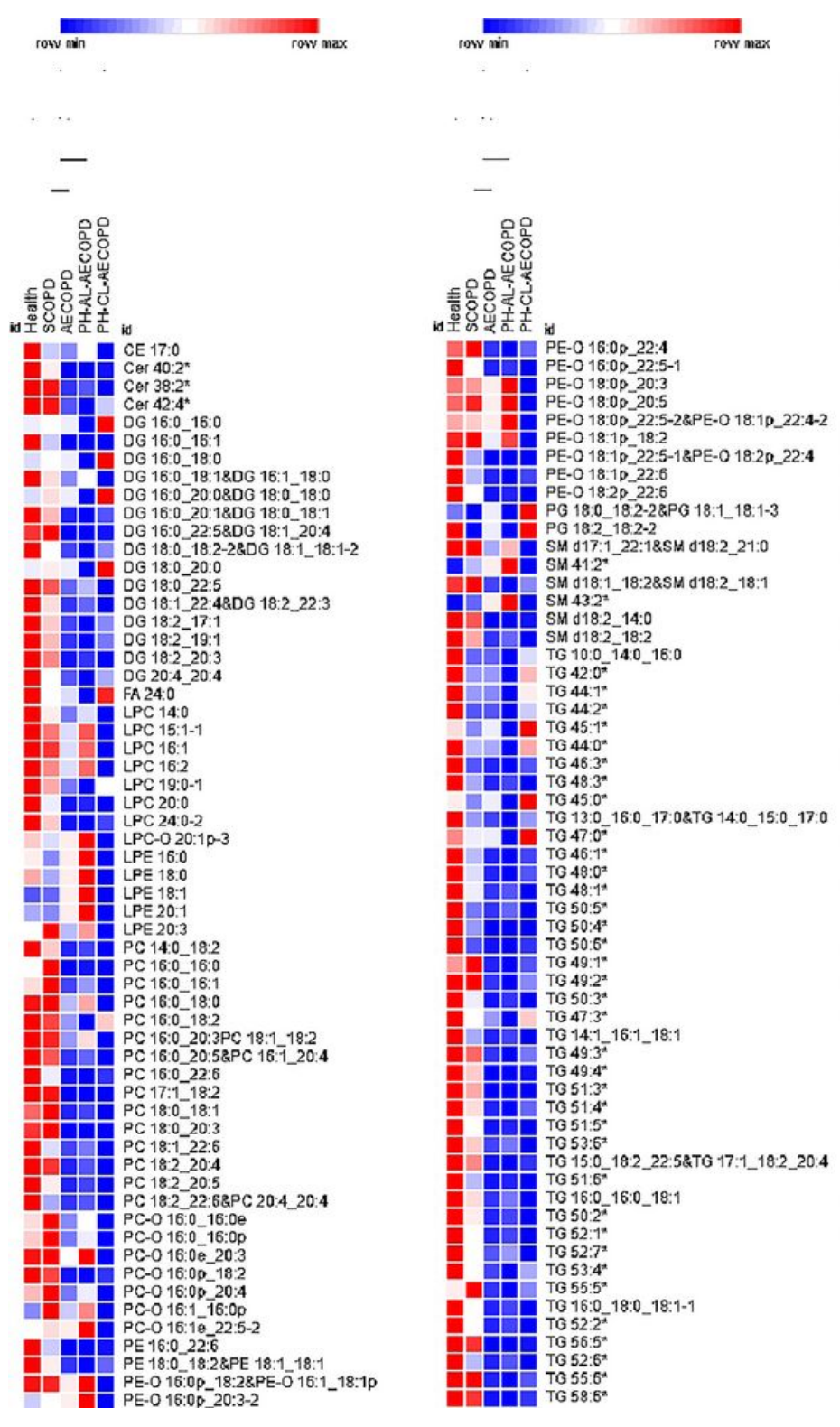

Identification of lipids marked with $\left(^{*}\right)$

\begin{tabular}{|c|c|}
\hline Cer 40:2 & Cer d16:1_24:1 \& Cer d17:1_23:4 \& Cer d18:0_22:2 \& Cer d18:1_22:1 \& Cer d18:2_22:0 \\
\hline Cer $38: 2$ & Cer d17:1_21:1 \& Cer d18:1_20:1 \& Cer d18:2_20:0 \\
\hline Cer 42:4 & Cer d17:1_25:3 \& Cer d18:1_24:3 \& Cer d18:2_24:2 \\
\hline SM 41:2 & SM d17:1_24:1 \& SM d18:1_23:1 \& SM d18:2_23:0 \\
\hline SM 43:2 & SM d18:1_25:1 \& SM d18:2_25:0 \& SM d19:1_24:2 \\
\hline TG 42:0 & IG $10: 0 \_14: 0 \_18: 0 \&$ TG 14:0_12:0_16:0\& TG 14:0_14:0_14:0 \\
\hline TG 44:1 & IG $10: 0$ _16:0_18:1 \& TG 12:0_14:0_18:1 \& TG 12:1_16:0_16:0 \& TG 14:0_14:0_16:1 \\
\hline TG 44:2 & 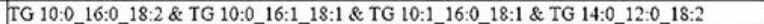 \\
\hline TG 45:1 & $\begin{array}{l}\text { TG 12:0_15:0_18:1 \& TG 12:0_16:0_17:1 \& TG 12:1_15:0_18:0 \& TG 12:1_16:0_17:0 \& TG } \\
13: 0 \_15: 0 \_17: 1 \text { \& TG 14:0_15:0_16:1 }\end{array}$ \\
\hline IG 44:0 & $\begin{array}{l}\text { TG 12:0_16:0_16:0 \& TG 13:0_13:0_18:0\& TG 13:0_15:0_16:0 \& TG 14:0_15:0_15:0 \& TG } \\
14: 0: 16: 0 \_16: 0\end{array}$ \\
\hline IG 46:3 & TG 12:0_16:1_18:2\& TG 14:0_16:1_16:2\& TG 14:1_16:1_16:1 \& TG 14:2_16:0_16:1 \\
\hline TG 48:3 & $\begin{array}{l}\text { TG 12:0_18:1_18:2 \& TG 12:1_18:1_18:1 \& TG 14:0_16:1_18:2 \& TG 14:1_16:0_18:2 \& TG } \\
16: 016: 0 \text { 16:3 \& TG 16:0_16:1_16:2 \& TG 16:1_16:1_6:1 }\end{array}$ \\
\hline IG 45:0 & TG 13:0_16:0_16:0\& TG 13:0_17:0_15:0\& TG 14:0_15:0_16:0 \& TG 15:0_15:0_15:0 \\
\hline IG 47:0 & IT 14:0_15:0_18:0\& TG 14:0_16:0_17:0\& TG 15:0_16:0_16:0 \\
\hline IG 46:1 & TG 14:0_16:0_16:1 \& TG 12:0_16:0_18:1 \& TG 14:0_14:0_18:1 \\
\hline IG 48:0 & IG 14:0_16:0_18:0\& TG 15:0_16:0_17:0\& TG 16:0_16:0_16:0 \\
\hline IG 48:1 & TG 14:0_16:0_18:1 \& TG 15:0_16:1_17:0\& TG 16:0_16:0_16:1 \\
\hline TG 50:5 & $\begin{array}{l}\text { TG 14:0_16:0_20:5 \& TG 14:0_18:1_18:4\& TG 14:0_18:2_18:3 \& TG 14:1_16:0_20:4 \& TG } \\
14: 1 \_18: 1 \_18: 3 \& \text { TG } 14: 1 \_18: 2 \_18: 2 \& \text { TG } 16: 0 \_16: 1 \_18: 4\end{array}$ \\
\hline TG 50:4 & $\begin{array}{l}\text { TG 14:_16:1_20:3 \& TG 14:1_16:0_20:3 \& TG 16:0 16:0_18:4 \& TG 16:0_16:1_18:3 \& TG } \\
16: 0 \_16: 2 \_18: 2 \& \text { TG 16:0_16:3 18:1 \& TG 16:1_16:1_18:2 }\end{array}$ \\
\hline IG 50:6 & $\begin{array}{l}\text { TG 14:0_16:1_20:5 \& TG 14:0_16:2_20:4 \& TG 14:0_18:3_18:3 \& TG 16:0_16:1_18:5 \& TG } \\
\text { 16:1_16:1_18:4 \& TG 15:0_16:0_18:0\& TG 16:0_16:0_17:0 }\end{array}$ \\
\hline TG 49:1 & $\begin{array}{l}\text { TG 14:0_17:0_18:1 \& TG 15:0_16:0_18:1 \& TG 15:1_16:0_18:0 \& TG 16:0_16:0_17:1 \& TG } \\
16: 0 \_16: 1117: 0\end{array}$ \\
\hline TG 49:2 & 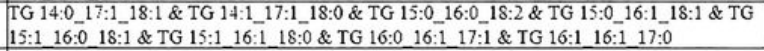 \\
\hline IG 50:3 & TG 14:0_18:1_18:2 \& TG 16:0_16:1_18:2-1 \& TG 16:0_16:2_18:1 \& TG 16:1_16:1_18:1 \\
\hline IG 47:3 & TG 14:1_16:1_17:1 \& TG 15:1_16:1_16:1 \& TG 15:2_16:0_16:1 \\
\hline TG 49:3 & $\begin{array}{l}\text { TG 14:1_17:1_18:1 \& TG 15:0_16:0_18:3 \& TG 15:0_16:1_18:2 \& TG 15:1_16:0_18:2 \& TG } \\
15: 1 \_16: 1 \_18: 1 \text { \& TG 15:2_16:0_18:1 \& TG 16:1_16:1_17:1 }\end{array}$ \\
\hline TG 49:4 & 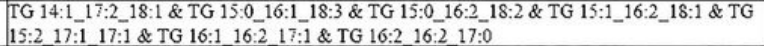 \\
\hline TG 51:3 & $\begin{array}{l}\text { TG 15:0_18:1_18:2 \& TG 15:1_18:1_18:1 \& TG 16:0_17:1_18:2 \& TG 16:1_17:0_18:2 \& TG } \\
16: 1 \_17: 1118: 1\end{array}$ \\
\hline TG 51:4 & $\begin{array}{l}\text { TG 15:0_18:1_18:3 \& TG 15:0_18:2_18:2 \& TG 15:1_18:1_18:2 \& TG 16:0_17:2_18:2 \& TG } \\
16: 1 \text { T } 17: 118: 2 \& \text { TG 16:1_17:2_18:1 \& TG } 16: 2 \text { 17:1_18:1 }\end{array}$ \\
\hline TG 51:5 & TG $15: 0 \_18: 2 \_18: 3 \&$ TG $15: 1 \_18: 2 \_18: 2 \&$ TG 16:0_17:1_18:4 \& TG 16:1_17:1_18:3 \\
\hline IG 53:6 & $\begin{array}{l}\text { TG 15:0_18:2_20:4 \& TG 17:2_18:2_18:2-2 \& TG 17:0_18:1_18:3 \& TG 17:2_18:2_18:2-1 \& } \\
\text { TG 17:1_18:1_18:4 }\end{array}$ \\
\hline IG 51:6 & TG $15: 0 \_18: 3 \_18: 3 \&$ TG $15: 1$ _18:2_18:3\& TG $15: 2$ _18:2_18:2 \\
\hline IG 50:2 & TG 16:0_16:0_18:2\& TG 16:0_16:1_18:1 \& TG 16:0_17:1_17:1 \\
\hline IG 52:1 & IG $16: 0 \_16: 0$ _20:1 \& TG 16:0_17:0_19:1 \& TG 16:0_18:0_18:1-2 \\
\hline TG 52:7 & TG $16: 0$ _16:0_20:7 \& TG 16:0_16:1_20:6\& TG 16:1_16:1_20:5 \& TG 16:1_18:2_18:4 \\
\hline TG 53:4 & $\begin{array}{l}\text { TG 16:0_17:0_20:4 \& TG 16:1_17:1_20:2 \& TG 17:0_18:2_18:2 \& TG 17:1_17:1_19:2 \& TG } \\
\text { 17:1_18:0_18:3 \& TG 17:1_18:1_18:2 }\end{array}$ \\
\hline TG 55:5 & 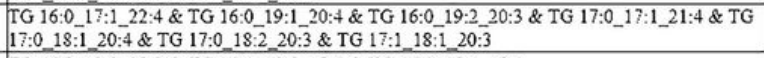 \\
\hline IG 52:2 & TG 16:0_18:0_18:2\& TG 16:1_18:0_18:1 \& TG 16:0_18:1_18:1 \\
\hline TG 56:5 & $\begin{array}{l}\text { TG 16:0_18:1__22:4 \& TG 16:0_20:1__20:4 \& TG 16:0_20:2_20:3 \& TG 16:1_18:2_22:4 \& TG } \\
\text { 18:0_18:0_20:5 }\end{array}$ \\
\hline TG 52:6 & $\begin{array}{l}\text { TG 16:1_16:1_20:4 \& TG 16:1_18:2_18:3 \& TG 16:0_18:2_18:3 \& TG 16:1_16:1_20:3 \& TG } \\
16: 1 \_18: 2 \_18: 2\end{array}$ \\
\hline IG 55:6 & TG 17:0_18:1_20:5\& TG 17:0_18:2_20:4\& TG 17:1_18:1_20:4 \\
\hline TG 58:6 & $22: 4 \&$ TG 18:1_18:2_22:3 \& TG 18:2_18:2_22:2 \& TG \\
\hline
\end{tabular}

Figure 5

Heat map of the 118 differential metabolites detected in COPD at different stages and in different TCM syndromes; the color change from blue to red indicates an increasing number of metabolites. Lipids marked with an asterisk $\left(^{*}\right)$ are listed in the table to the right. AECOPD, acute exacerbation of chronic obstructive pulmonary disease; CE, cholesterol ester; Cer, ceramide; DG, diacylglycerol; FA, fatty acid; Health, healthy subjects; LPC, lyso-phosphatidylcholine; LPC-0, lyso-phosphatidylcholine with alkyl substituents; LPE, lysophosphatidylethanolamine; PC, phosphatidylcholine; PC-O, alkyl- and alkenyl-substituted phosphatidylcholine; PE, phosphatidylethanolamine; PE-O, alkyl- and alkenyl-substituted phosphatidylethanolamine; PG, phosphatidylglycerol; PH-CL, phlegm-heat congesting lung; PH-AL, phlegm-damp amassing in the lung; SCOPD, stable chronic obstructive pulmonary disease; SM, sphingomyelin;

TG, triacylglycerol. 


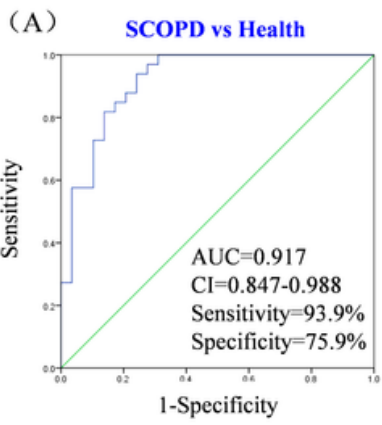

PH-CL-AECOPD vs SCOPD

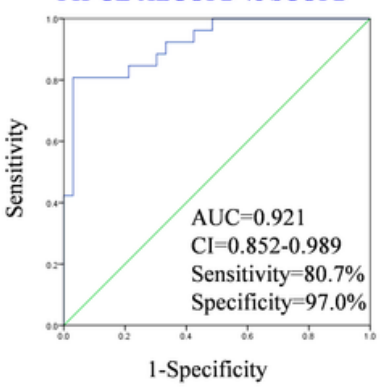

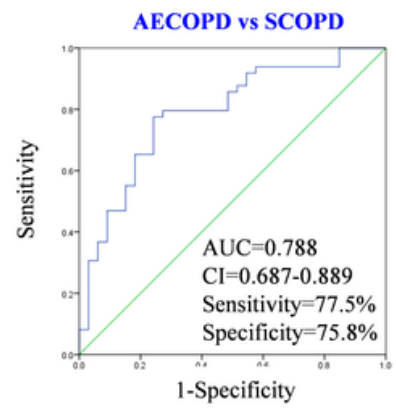

PH-AL-AECOPD vs SCOPD

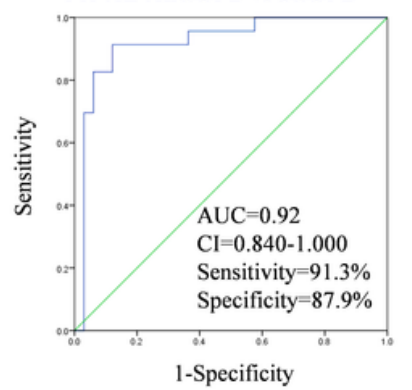

(B)
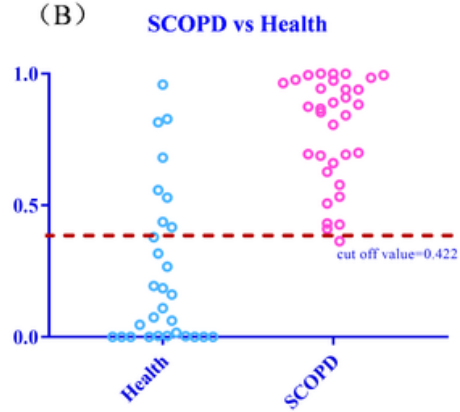

PH-CL-AECOPD vs SCOPD

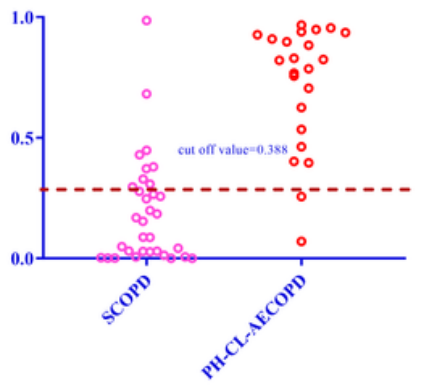

AECOPD vs SCOPD

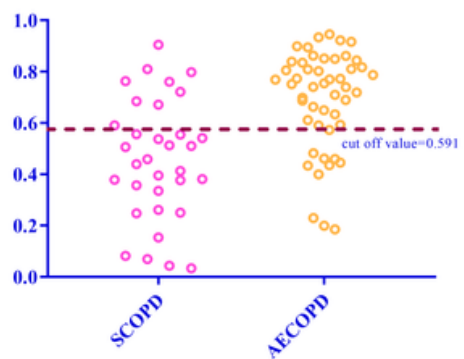

PH-AL-AECOPD vs SCOPD

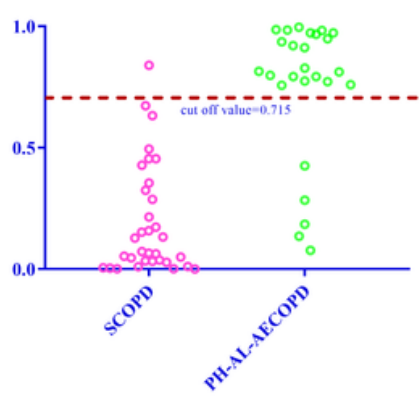

\section{Figure 6}

(A) Diagnostic utility of differential lipids as determined by receiver operating characteristic (ROC) curve analysis. (B) Diagnostic accuracy of the biomarkers. AECOPD, acute exacerbation of chronic obstructive pulmonary disease; AUC, area under the receiver operating characteristic curve; $\mathrm{Cl}$, confidence interval; Health, healthy subjects; $\mathrm{PH}-\mathrm{CL}$, phlegm-heat congesting lung; $\mathrm{PH}-\mathrm{AL}$, phlegm-damp amassing in the lung; SCOPD, stable chronic obstructive pulmonary disease; VIP, variable importance in projection.

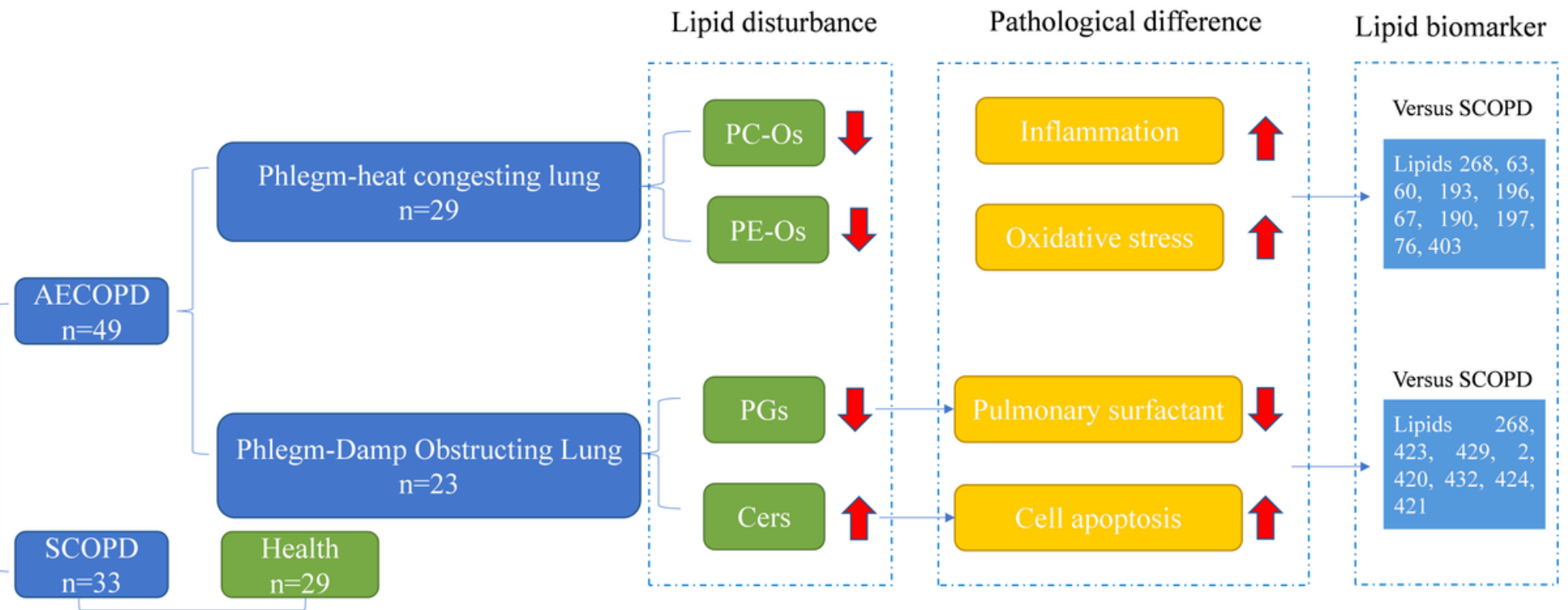

\section{Figure 7}

Protocol for AECOPD diagnosis using lipidomics biomarkers. AECOPD, acute exacerbation of chronic obstructive pulmonary disease; Cers, ceramides; Health, healthy subjects; PC-O, alkyl- and alkenyl-substituted phosphatidylcholine; PE-0, alkyl- and alkenyl-substituted phosphatidylethanolamine; PG, phosphatidylglycerol; SCOPD, stable chronic obstructive pulmonary disease.

\section{Supplementary Files}

This is a list of supplementary files associated with this preprint. Click to download. 
- Supplemantarymaterials2.docx

Page 25/25 